Article

\title{
An Estimation of Hydraulic Power Take-off Unit Parameters for Wave Energy Converter Device Using Non-Evolutionary NLPQL and Evolutionary GA Approaches ${ }^{\dagger}$
}

\author{
Mohd Afifi Jusoh, Mohd Zamri Ibrahim *(D), Muhamad Zalani Daud (D), Zulkifli Mohd Yusop and Aliashim Albani (1) \\ Renewable Energy \& Power Research Interest Group (REPRIG), Eastern Corridor Renewable Energy Special \\ Interest Group, Faculty of Ocean Engineering Technology and Informatics, Universiti Malaysia Terengganu, \\ Kuala Nerus 21030, Terengganu, Malaysia; mohd.afifi.jusoh@gmail.com (M.A.J.); zalani@umt.edu.my (M.Z.D.); \\ zul_12521@yahoo.com (Z.M.Y.); a.albani@umt.edu.my (A.A.) \\ * Correspondence: zam@umt.edu.my; Tel.: +60-96683328 \\ † This paper is an extended and revised article presented at the International Conference on Sustainable Energy \\ and Green Technology 2019 (SEGT 2019) on 11-14 December 2019 in Bangkok, Thailand.
}

Citation: Jusoh, M.A.; Ibrahim, M.Z.; Daud, M.Z.; Yusop, Z.M.; Albani, A. An Estimation of Hydraulic Power Take-off Unit Parameters for Wave Energy Converter Device Using Non-Evolutionary NLPQL and Evolutionary GA Approaches ${ }^{\dagger}$. Energies 2021, 14, 79.

https://dx.doi.org/10.3390/en14010079

\section{Received: 2 December 2020}

Accepted: 20 December 2020

Published: 25 December 2020

Publisher's Note: MDPI stays neutral with regard to jurisdictional claims in published maps and institutional affiliations.

Copyright: () 2020 by the authors. Licensee MDPI, Basel, Switzerland. This article is an open access article distributed under the terms and conditions of the Creative Commons Attribution (CC BY) license (https: / / creativecommons.org/ licenses/by/4.0/).

\begin{abstract}
This study is concerned with the application of two major kinds of optimisation algorithms on the hydraulic power take-off (HPTO) model for the wave energy converters (WECs). In general, the HPTO unit's performance depends on the configuration of its parameters such as hydraulic cylinder size, hydraulic accumulator capacity and pre-charge pressure and hydraulic motor displacement. Conventionally, the optimal parameters of the HPTO unit need to be manually estimated by repeating setting the parameters' values during the simulation process. However, such an estimation method can easily be exposed to human error and would subsequently result in an inaccurate selection of HPTO parameters for WECs. Therefore, an effective approach of using the non-evolutionary Non-Linear Programming by Quadratic Lagrangian (NLPQL) and evolutionary Genetic Algorithm (GA) algorithms for determining the optimal HPTO parameters was explored in the present study. A simulation-optimisation of the HPTO model was performed in the MATLAB/Simulink environment. A complete WECs model was built using Simscape Fluids toolbox in MATLAB/Simulink. The actual specifications of hydraulic components from the manufacturer were used during the simulation study. The simulation results showed that the performance of optimal HPTO units optimised by NLPQL and GA approaches have significantly improved up to $96 \%$ and $97 \%$, respectively, in regular wave conditions. The results also showed that both optimal HPTO units were capable of generating electricity up to $62 \%$ and $77 \%$, respectively, of their rated capacity in irregular wave circumstances.
\end{abstract}

Keywords: wave energy converter; hydraulic power take-off unit; parameter estimation; genetic algorithm; non-linear programming by quadratic Lagrangian

\section{Introduction}

Ocean waves are one of the renewable energy resources that potentially can be exploited to produce usable electricity due to their excellent features of predictability, high energy density and high source availability [1,2]. Currently, numerous wave energy converters (WECs) have been designed, developed, tested and patented through a variety of harnessing techniques that are subjected to the characteristics of the target location such as shoreline, nearshore and offshore, as reported in [3-6]. In general, WECs are a combination of three main parts, such as a wave energy converter (WEC) device, power take-off (PTO) unit and control system unit. Recently, various types of PTO units have been developed for WEC devices based on different working principles, such as the air and water turbinebased, direct-electrical drive-based, direct-mechanical drive-based and hydraulic-based, as reported in $[7,8]$. A hydraulic PTO (HPTO) is considered to be the most effective PTO 
for wave-activated-body (WAB) or point-absorber based WECs due to the outstanding features, including high-efficiency, high-controllability, well-adapted to the large power density ocean waves and low-frequency [9]. It has been reported in the literature that this type of PTO system's efficiency could be achieved up to 90\% [10]. Furthermore, the HPTO unit is also easily constructed using standard hydraulic components, which are commonly used in other applications. Due to such a promising characteristic, the HPTO system finds its application in the majority of the WAB-WECs field.

Recently, many HPTO unit applications in various WECs have been published [11-17]. From the preliminary survey, most of the studies concentrated on the HPTO unit's efficiency without taking into account the optimal parameters of the HPTO model, such as hydraulic cylinder size, hydraulic accumulator capacity and pre-charge pressure and hydraulic motor displacement. The optimal configuration parameters of the HPTO unit is a crucial issue as it can affect the system's efficiency and the amount of output to be produced [13]. Only a few reports, for example, in [13-15], have considered this critical problem. However, the optimal parameters setting has been obtained by manually tuning these configuration parameters [13]. This method is usually prone to human error and easy to cause a non-optimal selection of the HPTO system's parameters. In addition, this approach also frequently involves a long-time process in order to obtain the optimal configuration parameters.

Presently, the optimisation of design parameters using a mathematical algorithm is an attractive method to estimate the accurate parameters during the design phase. It is due to the advancement of fast computing technologies that can be reliably used. A variety of studies were performed using different types of mathematical algorithms, such as non-linear programming by quadratic Lagrangian (NLPQL) and genetic algorithm (GA), Particle Swarm Optimization (PSO), Ant Colony Optimization (ACO), Tabu Search (TS), et cetera, in order to obtain the best parameters for the design model [18-23]. For example, GA has been used to optimise the parameters of state-of-charge (SOC) controllers for battery energy storage in photovoltaic device applications [21]. The authors emphasized that the GA-based optimisation method has accelerated the optimisation process of the considered design parameters and effectively improves the design model's performance. Similarly, in [22], different types of heuristic optimisation approaches were applied, including Gravitational Search Algorithm (GSA) and PSO, to conduct model optimization-based studies for improving the efficiency of developed power converter units. The authors had concluded that GSA-based optimisation provides the highest convergence speed and best fitness value compared to the other algorithms. Motivated by the studies presented in [21,22], an optimized new design of WEC with an HPTO unit is presented in this study.

From the WECs point of view, a similar optimisation approach has been implemented in optimising the performance of the WECs. From the preliminary survey, several studies of the GA applications for WECs optimisation have been done [24-28]. For example, in [24], GA has been used to obtain some WECs parameters, such as buoy radius, draft, generator damping and the optimal spatial layout of a WECs park. In [25], GA has been adopted to optimally design the shape and dimensions of a WEC and also the PTO and other subsystems parameters. The techno-economic aspects of energy productivity and WECs device cost have also been considered in the study. In [28], GA has been used to obtain the optimal HPTO parameters of WECs, such as hydraulic cylinder size, hydraulic accumulator capacity and pre-charge pressure, and hydraulic motor displacement without considering the hydrodynamic effects of the floater. Since the hydrodynamic effects of the floater are the vital factors in WECs design, the optimal HPTO obtained in the study is inapplicable for real wave application. Therefore, the HPTO optimisation with the consideration of the floater's hydrodynamic effects using two different types of algorithm, such as NLPQL and GA, were investigated in this present study. The optimisation approaches presented in this study can be a useful reference to other researchers and engineers of WECs in order to design an accurate and reliable HPTO unit for the future WECs application. 
The paper is organised as follows. The technical descriptions of the considered WEC with HPTO unit and its important configuration parameters are given in Section 2. The simulation studies of the HPTO unit, which includes the simulation set-up process, optimisation process and evaluation of HPTO unit performance, are described in Section 3. Results and discussion are provided in Section 4, and finally, the Conclusions are given in Section 5 .

\section{Mathematical Modelling of WEC with HPTO Unit}

The design of the WECs depends on the characteristics of the installed location. In the present study, the rotation-based WEC attached to the fixed body concept was considered, as illustrated in Figure 1. This WECs concept has been implemented in numerous studies for various investigation goals, for example, in [29-32]. This concept is suitable to be installed at shoreline, nearshore and offshore locations. In this concept, the WEC device consists of a single or multiple floating buoy or floater attached to the rotatable arm and connected to the fixed body directed towards the dominant wave direction, as depicted in Figure 1. The multi-design of floater can be used, which is dependent on the direction of the ocean wave, either single or multi-direction. Usually, the semisphere-shaped and boatshaped floater have been considered for the offshore and nearshore location, as investigated in $[29,30,33-35]$. In this concept, the HPTO unit is utilised to convert the absorbed energy by the WEC device from the ocean wave to become usable electricity. A hydraulic actuator module of the HPTO unit is attached to the rotatable floater arm in order to absorb the mechanical energy produced by the WEC device, as presented in Figure 1. Meanwhile, the rest of the HPTO unit components are placed in the PTO house located on the top of the fixed-structure. In the present study, the model of WECs with a capacity of $0.1 \mathrm{~kW}$ was considered.

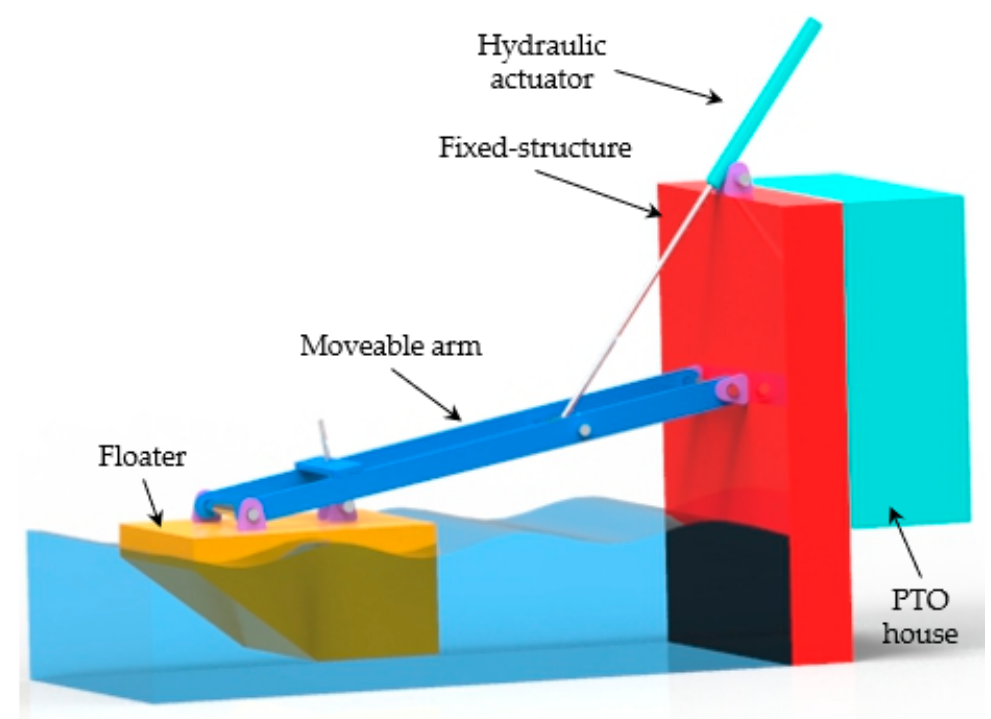

Figure 1. Conceptual design of future wave energy converter (WEC) with the hydraulic power take-off (HPTO) unit.

\subsection{Hydrodynamic Motion of the Floater}

In general, the hydrodynamic motion of the WEC device in real waves can be formulated in the time domain using the linear wave theory, as described in Equation (1). $M_{A}$ is the D'Alembert moment of inertia, $M_{e x}$ is the moment due to the diffracted waves, $M_{\text {rad }}$ is the moment due to radiated waves, $M_{r e s}$ is the hydrostatic restoring moment and $M_{P T O}$ is the moment due to the HPTO unit.

$$
M_{A}=M_{e x}-M_{r a d}-M_{r e s}-M_{P T O}
$$


The equation of the hydrodynamic motion in Equation (1) can be expended as given in Equation (2). Here, $J_{W E C}$ is the inertia moment of the floater and arm. Whereas, $J_{\text {add, }} \infty$ is the added mass at the infinite frequency and $\ddot{\theta}_{\text {arm }}$ is the angular acceleration of a WEC device during the pitch motion. Then, $k_{\text {rad }}(t)$ is the radiation impulse response function, $\tau$ is the time delay and $\dot{\theta}_{\text {arm }}$ is the angular velocity of the floater's arm. Other variables such as $k_{r e s}$ is the hydrostatic restoring coefficient and $\theta_{\text {arm }}$ is the angular of the floater's arm during the pitch motion. Finally, $h_{e x}(t-\tau)$ is the impulse response function of the excitation moment and $\eta_{W}$ is the undisturbed wave elevation at the floater center point.

$$
\left(J_{W E C}+J_{a d d, \infty}\right) \ddot{\theta}_{\text {arm }}(t)+\int_{0}^{t} k_{\text {rad }}(t-\tau) \dot{\theta}_{\text {arm }}(t)+k_{\text {res }} \theta_{\text {arm }}(t)+M_{\text {PTO }}(t)=\int_{-\infty}^{\infty} h_{e x}(t-\tau) \eta_{W}(\tau) d \tau
$$

The impulse response function in Equation (2) can be obtained from the hydrodynamic diffraction analysis using Computational Fluid Dynamics (CFD) software. In the present study, the hydrodynamic diffraction analysis of the WEC model was performed using ANSYS/AQWA software.

In addition, the moment due to the HPTO unit, $M_{P T O}$ can be defined using Equations (3)-(5), where $F_{P T O}$ is the feedback force from the HPTO unit applied to the WEC device. The variables $L_{1}, L_{2}, L_{3}$ and $L_{4}$ are the lengths between point $a, b, c$ and $d$, as illustrated in Figure 2 [30,36-38]. $x_{p}$ is the displacement of hydraulic cylinder piston and $L_{3,0}$ is the initial stroke of the hydraulic cylinder.

$$
\begin{gathered}
M_{\text {РTO }}=F_{P T O} L_{4} \\
L_{4}=\frac{L_{1} L_{2} \sin \left(\theta_{\text {arm }, 0}-\theta_{\text {arm }}\right)}{L_{3,0}+x_{c}} \\
x_{p}=L_{3,0}-\sqrt{L_{1}^{2}+L_{2}^{2}-2 L_{1} L_{2} \cos \left(\theta_{\text {arm }, 0}-\theta_{\text {arm }}\right)}
\end{gathered}
$$
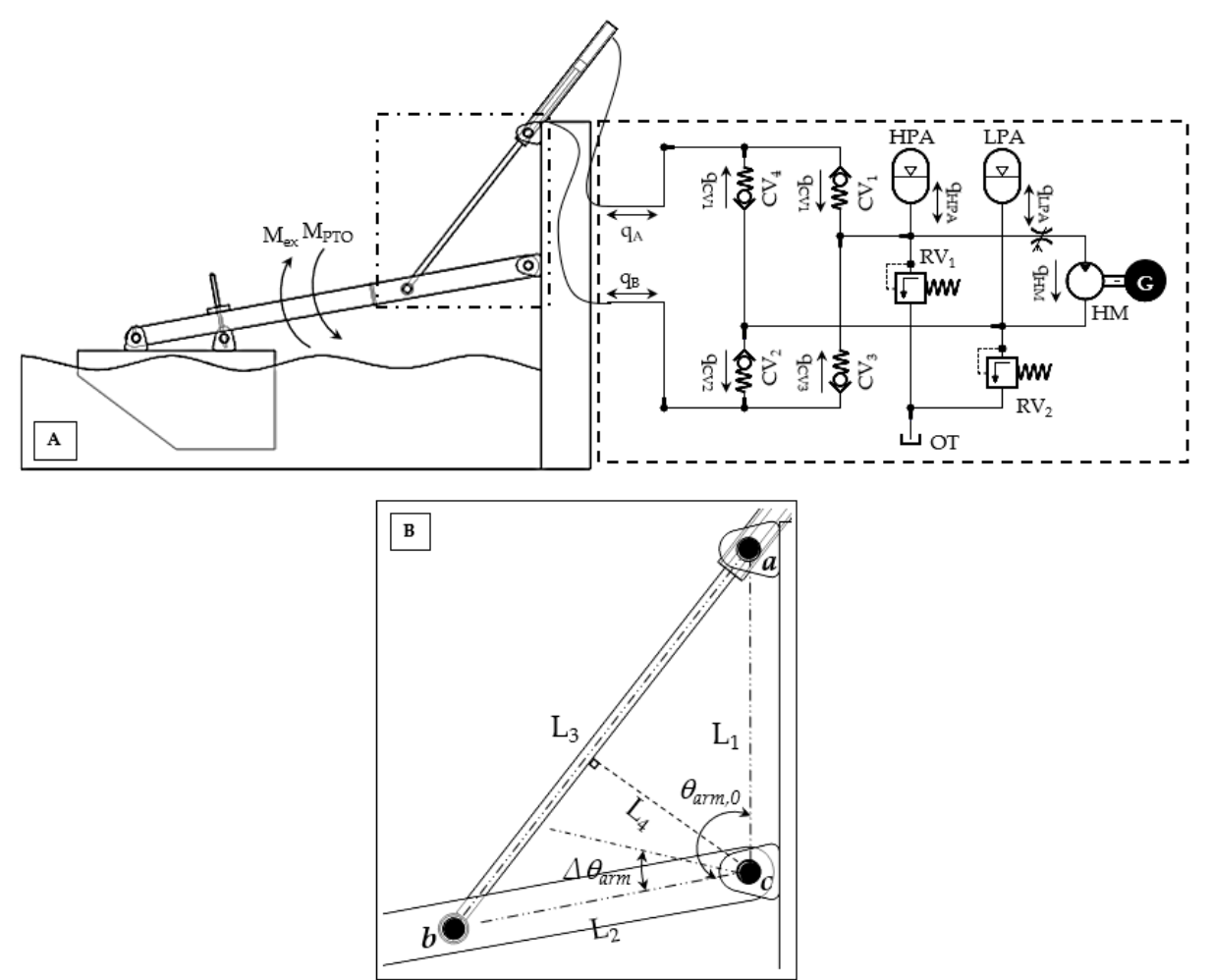

Figure 2. (A) Illustration of WEC with HPTO unit and (B) Configuration of hydraulic cylinder motion. 


\subsection{Hydraulic Power Take-off (HPTO) Mechanism}

Figure 2A illustrates the considered HPTO unit, which includes a hydraulic actuator, set of control check valves (CV), high-pressure and low-pressure accumulator (HPA and LPA), hydraulic motor (HM) and electrical generator (G). In the HPTO unit, the large chamber of the hydraulic cylinder (chamber $\mathrm{A}$ ) is connected to the $C V_{4}$ (outlet) and $C V_{1}$ (inlet), while the small chamber of DAC (chamber B) is connected to the $C V_{2}$ (outlet) and $\mathrm{CV}_{3}$ (inlet), respectively. Meanwhile, HPA and LPA are placed at the inlet and outlet of the hydraulic motor. During the operation, the wave force generated from the passing ocean wave causes a floater to swing upward and downward repeatedly, as illustrated in Figure 2B. The mechanical force produced by the WEC device forces the rod and piston of the hydraulic cylinder at the specified velocity $\left(\dot{x}_{p}\right)$ relatively subjected to the PTO load force. During the upward motion, the high-pressurised fluid in chamber A flows to the chamber B through $C V_{1}, \mathrm{HPA}, \mathrm{HM}, \mathrm{LPA}$ and $C V_{2}$. On the other hand, the process is vice-versa during downward motion, where high-pressure fluid in chamber B flows to chamber $\mathrm{A}$ through $\mathrm{CV}_{3}, \mathrm{HPA}, \mathrm{HM}, \mathrm{LPA}$ and $C V_{4}$. The high-pressure fluid flows through HM lead to the $\mathrm{HM}$, and $\mathrm{G}$ rotates simultaneously at the specified rotation speed $\left(\omega_{G}\right)$ subjected to the load torque of the $G\left(\tau_{G}\right)$. As a result, the usable electricity can be generated by the continuous motion of this mechanism.

In general, the behaviour of the HPTO unit is strongly nonlinear. Equations (6)-(21) theoretically explain the operation of the considered HPTO unit illustrated in Figure 2. According to Equation (6), the $F_{P T O}$ from the HPTO unit applied to the WEC device depends on the pressure in both hydraulic chambers $\left(p_{A}\right.$ and $\left.p_{B}\right)$ and the effective piston area $\left(A_{P}\right)$. Further, the effects of piston friction $\left(F_{\text {fric }}\right)$ and initial force of rod, piston and oil $\left(F_{i n}\right)$ are also considered. These effects can be expressed using Equations $(7)$ and $(8)$, where $\eta_{\text {fric }}$ is a friction coefficient, $\ddot{x}_{p}$ is the piston acceleration, $g$ is a gravitational acceleration, $M_{p}, M_{r}$ and $M_{o i l}$ are the mass of the piston, rod, and oil, respectively [12,36].

$$
\begin{gathered}
F_{\text {РТO }}=A_{p}\left(\left|p_{A}-p_{B}\right|\right)+F_{\text {fric }}+F_{i n} \\
F_{\text {fric }}=\left|A_{p}\left(p_{B}-p_{A}\right)\right|\left(1-\eta_{\text {fric }}\right) \\
F_{\text {in }}=\ddot{x}_{p}\left(M_{p}+M_{r}+M_{\text {oil }}\right)+\left(M_{p}+M_{r}\right) g
\end{gathered}
$$

Since a double-acting-cylinder with a single rod piston is considered a hydraulic

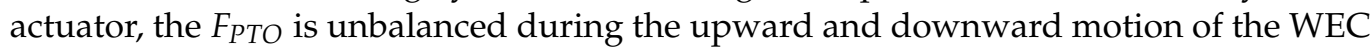
device due to the unbalanced pressure in both chambers of the hydraulic cylinder. Based

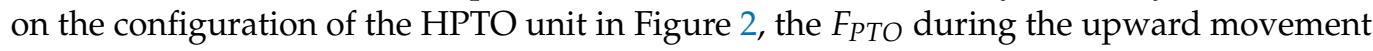
is greater than the $F_{\text {РTO }}$ during the downward movement. The dynamics of $p_{A}$ and $p_{B}$ can be described using a fluid continuity equation as in Equations (9) and (10) [12,37]. $\beta_{\text {eff }}, q_{A}$ and $q_{B}$ are the effective bulk modulus and the in/out volumetric flows in the hydraulic cylinder actuator. $x_{p}, \dot{x}_{p}$ and $L$ are position, velocity and stroke length of the piston. $A_{p, A}$ and $A_{p, B}$ are the effective piston area in the hydraulic chamber $\mathrm{A}$ and $\mathrm{B}$, that can be expressed by Equations (11) and (12), where the $d_{p}$ and $d_{r}$ are the diameter of the piston and rod, respectively.

$$
\begin{gathered}
\frac{d}{d t} p_{A}=\frac{\beta_{e f f}}{A_{p, A}\left(L-x_{p}\right)}\left(q_{A}-\dot{x}_{p} A_{p, A}\right) \\
\frac{d}{d t} p_{B}=\frac{\beta_{e f f}}{A_{p, B}\left(L-x_{p}\right)}\left(\dot{x}_{p} A_{p, B}-q_{B}\right) \\
A_{p, A}=\pi d_{p}{ }^{2} / 4 \\
A_{p, B}=\pi\left(d_{p}^{2}-d_{r}^{2}\right) / 4
\end{gathered}
$$


For the check valve, the spring-loaded non-return valves are used in this HPTO model. The flow across the valve $\left(q_{C V}\right)$ can be described by the orifice equation, as expressed in Equation (13), where $C_{d}$ is the discharge coefficient, $A_{C V}$ is the check valve opening area and $\rho_{\text {oil }}$ is the fluid density. The $p_{C V i n}$ and $p_{C V o u t}$ are the pressure at the inlet and outlet of the check valve $[12,38]$.

$$
q_{C V}=\left\{\begin{array}{c}
C_{d} A_{C V} \sqrt{2\left|p_{C V_{\text {in }}}-p_{C V_{\text {out }} \mid}\right| / \rho_{\text {oil }}}, \text { if } p_{C V_{\text {in }}}>p_{C V_{\text {out }}} \\
0, \text { else }
\end{array}\right.
$$

Besides that, the gas compression and expansion in the HPA and LPA, which are based on the isentropic process, can be described according to Equations (14) and (15), respectively. Where $p_{H P A}, p_{L P A}, p_{0, H P A}$ and $p_{0, L P A}$ are the pressure and pre-charge pressure in the HPA and LPA. $\gamma$ is the adiabatic index of the compressed gas in the HPA and LPA, while, $V_{H P A}, V_{L P A}, V_{0, H P A}$ and $V_{0, L P A}$ are the initial and the instantaneous volume of gas in the HPA and LPA, respectively. The instantaneous volume of gas can be expressed by Equations (16) and (17), where $q_{H P A}$ and $q_{L P A}$ are the volumetric flow in the HPA and LPA.

$$
\begin{gathered}
p_{H P A} \cdot V_{H P A}^{\gamma}=p_{0, H P A} \cdot V_{0, H P A}{ }^{\gamma} \\
p_{L P A} \cdot V_{L P A}^{\gamma}=p_{0, L P A} \cdot V_{0, L P A}{ }^{\gamma} \\
V_{H P A}(t)=V_{0, H P A}-\int_{0}^{t} q_{H P A} d t \\
V_{L P A}(t)=V_{0, L P A}-\int_{0}^{t} q_{L P A} d t
\end{gathered}
$$

Meanwhile, the fluid continuity in the HPTO model should satisfy the following equations:

$$
\begin{aligned}
& q_{H P A}=q_{C V_{1}}+q_{C V_{2}}-q_{H M} \\
& q_{L P A}=q_{C V_{3}}+q_{C V_{4}}-q_{H M}
\end{aligned}
$$

where $q_{H M}$ is the volumetric flow through the hydraulic motor. Here, $q_{H M}$ is given by Equation (20), where $D_{H M}, \omega_{H M}$, and $q_{H M, l o s s}$ are displacement, speed and volumetric flow losses of the hydraulic motor, respectively. The output torque of the hydraulic motor, $\tau_{H M}$ can be expressed by Equation (21), where $\Delta p_{H M}$ is the pressure difference in the hydraulic motor.

$$
\begin{gathered}
q_{H M}=D_{H M} \omega_{H M}-q_{H M, l o s s} \\
\tau_{H M}=D_{H M} \Delta p_{H M}
\end{gathered}
$$

Based on the theoretical descriptions provided in Equations (6)-(21), the most important component parameters, which influence the operation of the HPTO model can be defined as summarised in Table 1. The inaccuracy of the selected component parameters will reduce the HPTO unit's capability in converting the absorbed wave energy to electrical energy. Thus, the optimisation of these important component parameters using mathematical algorithms is considered in this study.

Table 1. Important component parameters of the HPTO system.

\begin{tabular}{ccc}
\hline No. & Parameter Setting & Unit \\
\hline 1 & Diameter of piston, $d_{p}$ & $\mathrm{~m}$ \\
2 & Diameter of rod, $d_{r}$ & $\mathrm{~m}$ \\
3 & Volume capacity of HPA, $V_{c a p, H P A}$ & $\mathrm{~L}$ \\
4 & Volume capacity of LPA, $V_{c a p, L P A}$ & $\mathrm{~L}$ \\
5 & Pre-charge gas pressure of HPA, $p_{0, H P A}$ & $\mathrm{Bar}$ \\
6 & Pre-charge gas pressure of LPA, $p_{0, L P A}$ & $\mathrm{Bar}$ \\
7 & Displacement of HM, $D_{H M}$. & $\mathrm{cc} / \mathrm{rev}$ \\
\hline
\end{tabular}




\section{Simulation Studies of WECs}

\subsection{Ocean Wave Input Data}

A previous study reported that the ranges of the wave height $\left(H_{W}\right)$ and wave period $\left(T_{W}\right)$ at several locations in Terengganu, Malaysia, were equal to the range of 0.2-1.2 $\mathrm{m}$ and 2-8 s, respectively [39]. In addition, a further forecast analysis found that the most annual occurrences sea-state at the considered installed location were equal to $0.8 \mathrm{~m}$ and $2.5 \mathrm{~s}$. From these statistical results, the regular and irregular wave inputs data were generated based on Airy's wave theory and Joint North Sea Wave Observation Project (JONSWAP) spectrum, as illustrated in Figure 3A,B, respectively. For the irregular wave data profile generation, the peak enhancement factor $(\gamma)$ of JONSWAP was set to 2 . Regular wave input profile data were used in determining the optimal parameters of the HPTO unit process. While the irregular wave input profile data were used to evaluate the effectiveness of the optimal HPTO unit in generating the electricity in inconsistent wave circumstances.

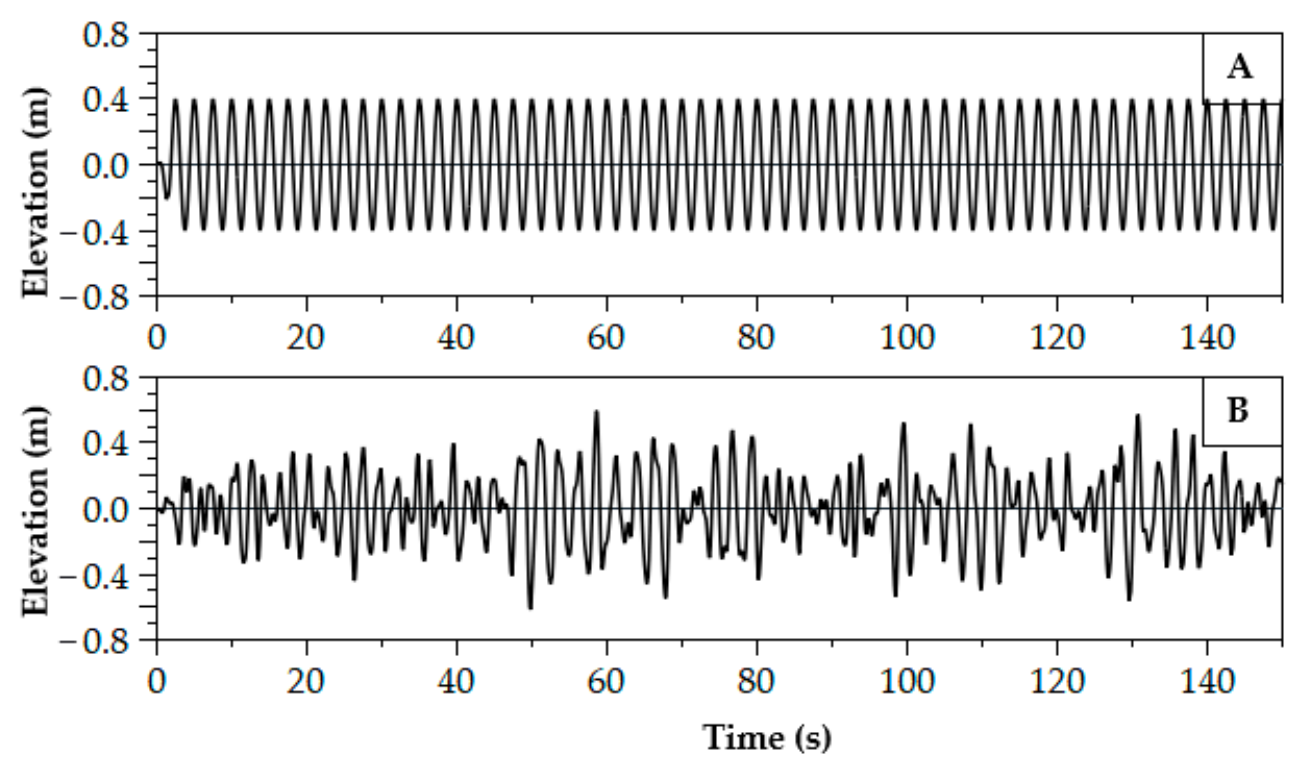

Figure 3. Ocean wave elevation inputs, (A) regular wave and (B) irregular wave.

\subsection{Simulation Set-up of WEC with HPTO Unit Model}

In the present study, the main specifications of the computer device that was used for the simulation studies are given in Table 2. As can be seen from Equations (1) and (2), the frequency domain analysis was required to determine the hydrodynamic parameters of the WEC device. Thus, hydrodynamic simulation of the WEC model was preliminarily performed using ANSYS/AQWA software. The hydrodynamic simulation method presented in $[40,41]$ was considered. The results from the preliminary hydrodynamic simulation are presented in Figure 4. The parameters obtained from the hydrodynamic simulation were used to build the complete simulation model of WEC with the HPTO unit in MATLAB ${ }^{\circledR 囚} /$ Simulink software, as illustrated in Figure 5. A WEC model based on the linear wave motion, as mentioned in Equations (1)-(5), was developed using the function blocks.

Table 2. Main specifications of the computer device.

\begin{tabular}{cc}
\hline Item & Details \\
\hline Type & Desktop \\
Windows & Windows 10 Pro \\
Memory (RAM) & $12 \mathrm{~GB}$ \\
CPU & Intel (R) Core (TM) i7-9750H 2.60 GHz \\
MATLAB Version & R2019b \\
\hline
\end{tabular}



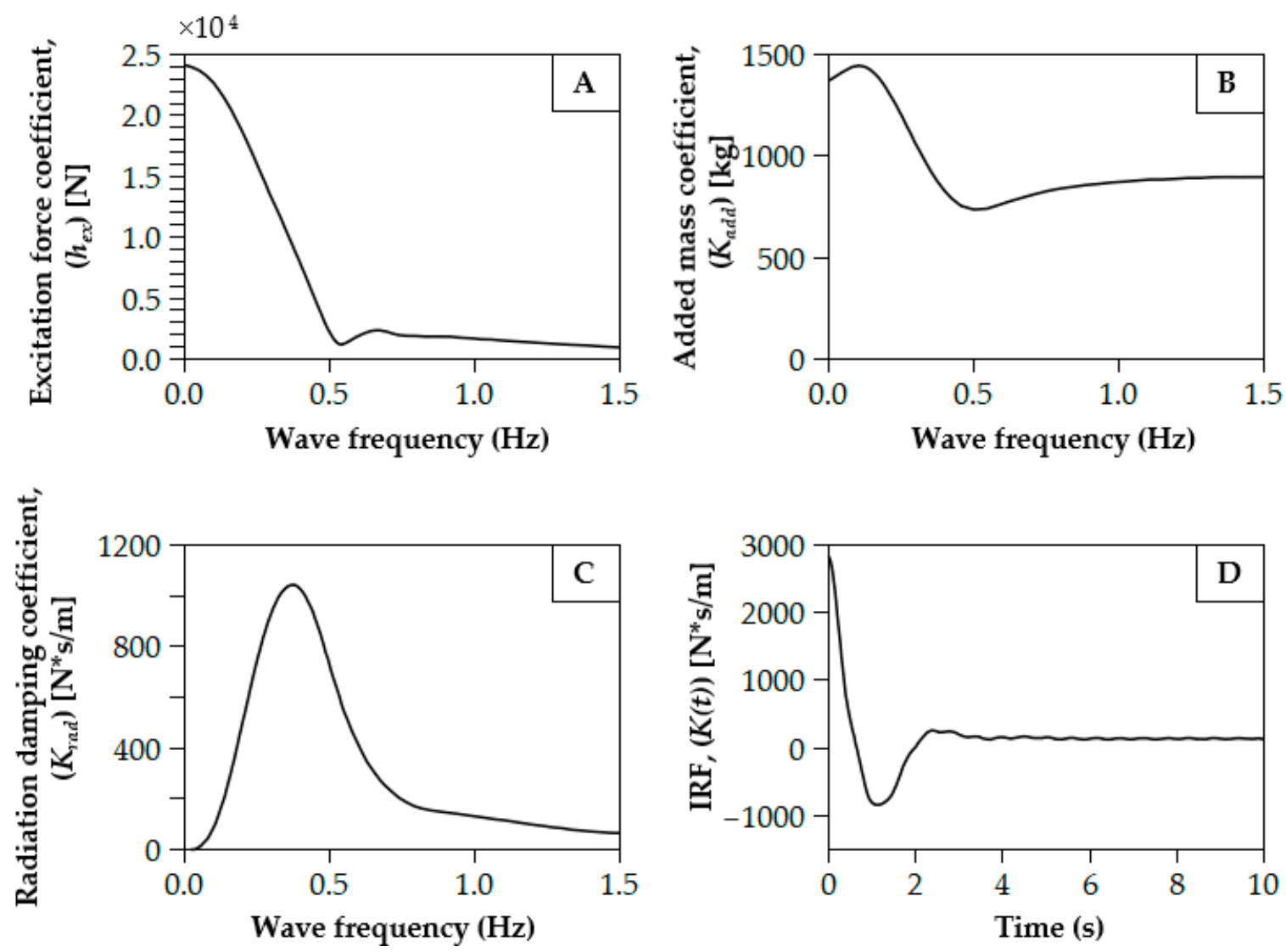

Figure 4. Hydrodynamic analysis parameters. (A) Excitation force coefficient, (B) added mass coefficient, (C) radiation damping coefficient, and (D) impulse response function.

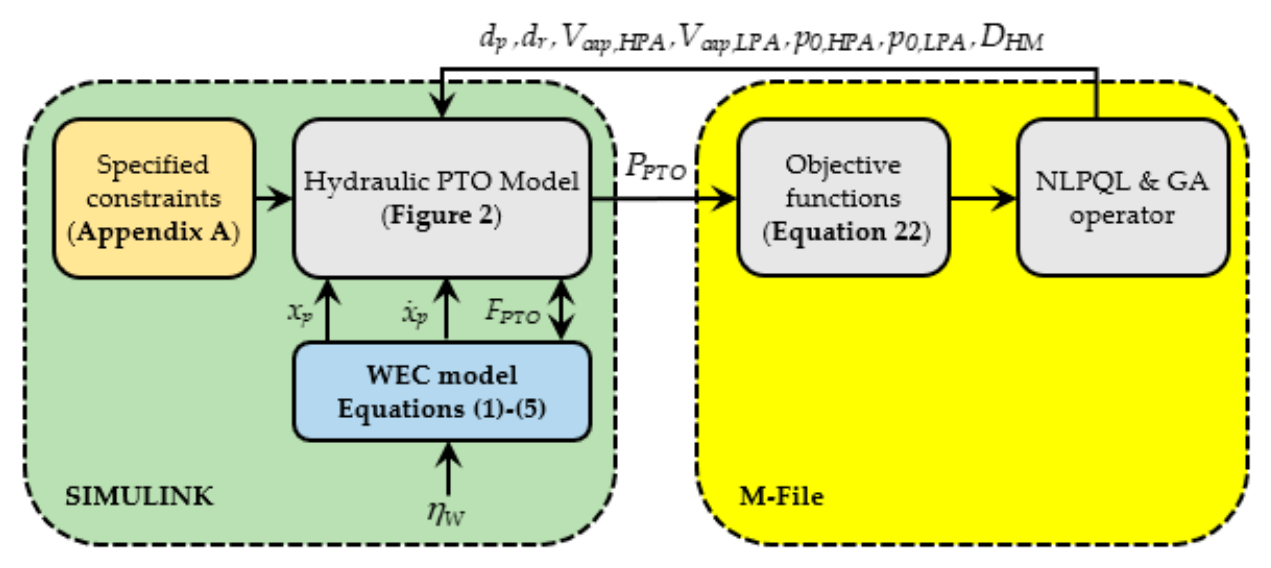

Figure 5. Illustration of simulation model set-up in MATLAB software.

Meanwhile, the HPTO model was developed using the hydraulic components in the Simscape Fluid toolbox, such as double hydraulic chamber single rod jack, hydraulic motor, hydraulic accumulator, hydraulic check valve with saturation, et cetera. The actual parameters of the hydraulic components from manufacturers were used to configure the HPTO model. Since the selection of the HPTO components was incredibly complex due to the variety of hydraulic products from the manufacturers and suppliers, the specification data of hydraulic components from a well-known manufacturer such as Parker Hannifin was considered, as summarised in Appendix A. The data in Appendix A were used as a guideline in determining the optimal configuration parameters of each element in the HPTO model simulation. 
Furthermore, a simple dynamic sub-model of a rotary load was utilised to represent the permanent magnet synchronous generator (PMSG) unit. The generated electrical power output from the HPTO model was calculated based on the speed-power curve of PMSG, which was obtained from the manufacturer. In addition, the PTO force, hydraulic motor torque, hydraulic motor speed and electrical power were the acquired outputs from the HPTO model. The detailed specifications of each component that were used in the HPTO model are presented in Table 3 .

Table 3. Technical specifications of the developed HPTO model.

\begin{tabular}{cc}
\hline Descriptions $($ Unit) & Value \\
\hline Generator & 0.1 \\
Rated power, $P_{\text {rated }}(\mathrm{kW})$ & 200 \\
Rated speed, $\omega_{G, \text { rated }}(\mathrm{rpm})$ & 6.0 \\
Rated torque $\tau_{G, \text { rated }}(\mathrm{Nm})$ & 0.024 \\
Viscous friction coefficient, $(\mathrm{Nm} / \mathrm{rpm})$ & 0.0036 \\
Moment of inertia, $\left(\mathrm{kgm}^{2}\right)$ & \\
Hydraulic cylinder & $0.035^{*}$ \\
Diameter of the piston, $d_{p}(\mathrm{~m})$ & $0.025^{*}$ \\
Diameter of the piston rod, $d_{r}(\mathrm{~m})$ & 0.3 \\
Length of stroke, $l_{\text {stroke }}(\mathrm{m})$ & 40 \\
HP accumulator & $8^{*}$ \\
Pre-charge gas pressure, $p_{0, H P A}(\mathrm{bar})$ & 1.4 \\
Volume capacity, $V_{\text {cap }, H P A}(\mathrm{~L})$ & \\
Adiabatic index, $\gamma$ & $5 *$ \\
LP accumulator & $2 *$ \\
Pre-charge gas pressure, $p_{0, L P A}(\mathrm{bar})$ & 1.4 \\
Volume capacity, $V_{\text {cap }, H P A}(\mathrm{~L})$ & \\
Adiabatic index, $\gamma$ & $8^{*}$ \\
Hydraulic motor & 50 \\
Displacement, $D_{H M}(\mathrm{cc} / \mathrm{rev})$ & 850 \\
Oil properties &
\end{tabular}

* Initial value by manual estimation.

Simulation results of the WEC with non-optimal HPTO unit using the regular waves input profile data are shown in Figure 6. Figure 6A shows that the displacement of WEC was relatively lower than the wave displacement due to the PTO force applied to the WEC device. The PTO force profile applied to the WEC device is shown in Figure 6B. The figure shows that the PTO forces applied to the WEC device during the upward and downward motion were equal to $1.5 \mathrm{kN}$ and $0.7 \mathrm{kN}$, respectively. Meanwhile, Figure $6 \mathrm{C}$ shows the electrical power generated from the non-optimal HPTO unit only can be reached up to an average of $71 \mathrm{~W}$, which was $71 \%$ of its rated capacity. 

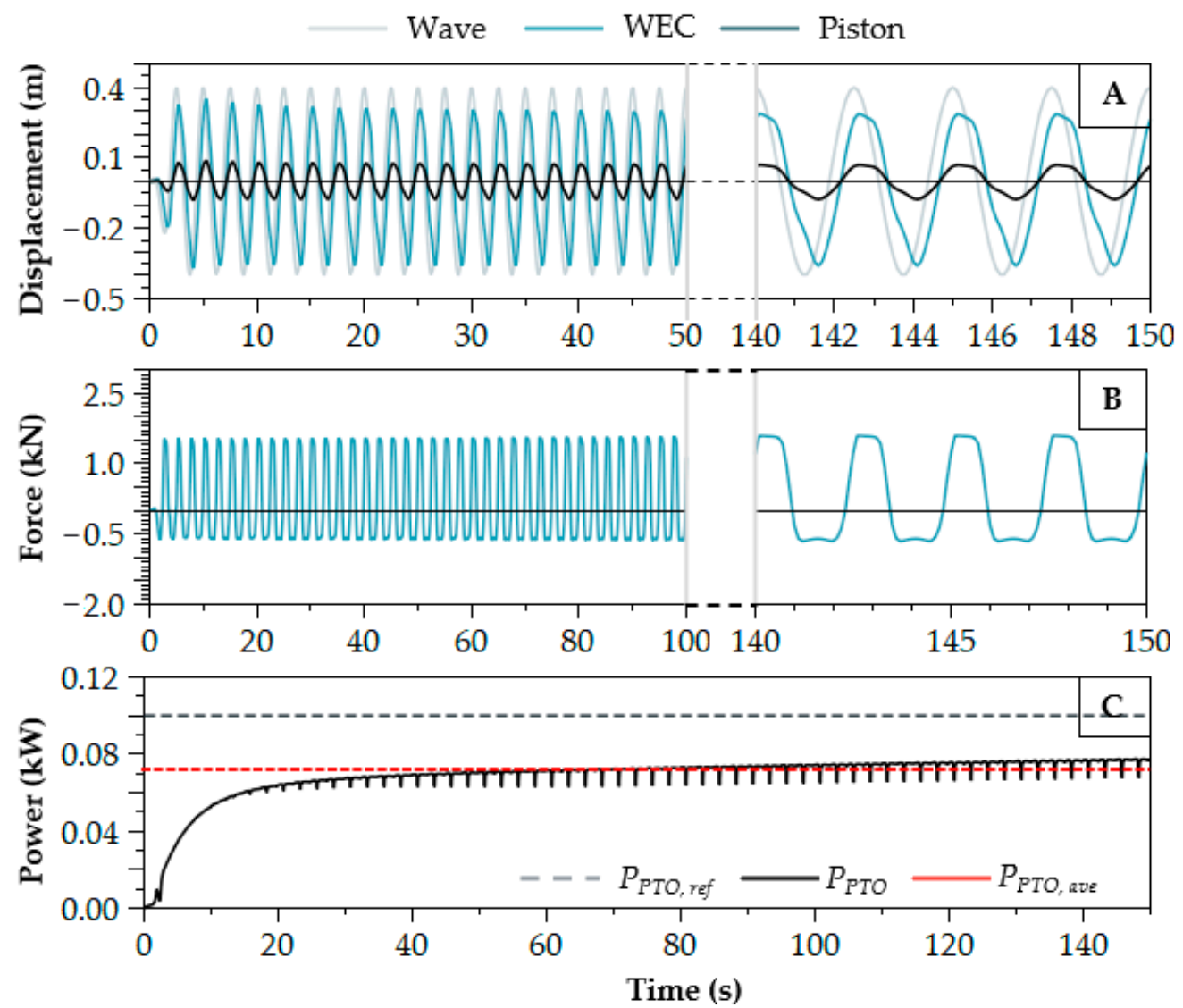

Figure 6. Preliminary simulation results of WEC with non-optimal power take-off (PTO) unit $\left(H_{W}=0.8, T_{W}=2.5 \mathrm{~s}\right)$. (A) Wave, WEC and piston displacements, (B) PTO force, and (C) PTO power.

\subsection{Optimisation of Configuration Parameter}

As the sea state was relatively unstable throughout the year, a suitable HPTO unit was compulsory for a WEC device to ensure that the ocean wave energy can be maximally absorbed and converted to electrical energy. Conventionally, the optimal parameters of the HPTO unit were obtained by iteratively simulating the HPTO model using any sophisticated analysis software. In this process, the designer was required to manually specify a set of configuration parameters value, evaluate the HPTO unit model and analyse the PTO model output. Normally, this process may be repeated many times due to unsatisfactory results from the HPTO performance. Consequently, the designer again proposed a new set of HPTO parameters value based on experience and intuition, which probably will result in a better output of the HPTO model. This optimisation process will end when the time runs out. Unfortunately, sophisticated analysis software and highspeed computer technology were unable to help the designer in determining the optimal parameters of the HPTO unit using this technique.

Alternatively, the optimisation technique HPTO unit parameters using a computer algorithm was presented in this study. By using this technique, the designer was taken out from the trial-and-error loop process. The sophisticated computer was now utilised to conduct a complete determination process of the optimal configuration parameters. Through this technique, the designer workload can be reduced, in which the designer only focused on the interpretation of the optimisation results. Moreover, the determination of the optimal configuration parameters can be found in a shorter and more accurate time compared to the case using a conventional technique. In the algorithm-based optimisation technique, many kinds of algorithms can be applied to solve the optimisation problem.

In the present study, the simulation-optimisation using two major types of optimisation algorithms was explored in this present study. A specific objective function (OF) was designed to maximise the electrical energy generation of the HPTO unit, as described 
in Equation (22). Here, $P_{P T O}$,ref and $P_{P T O}$ represented the desired and the actual electrical power output of the HPTO unit. The optimisation problem in Equation (22) was solved by two kinds of optimisation algorithms, i.e., NLPQL and GA. In order to provide a fairground for comparison between two optimisation algorithms, the same constraints, design parameters, and objective function were considered for both cases under study. The details of the considered algorithms are described in the following subsections.

$$
O F(x)=\min \left[\frac{\int_{0}^{T}\left(\left|P_{P T O}(t)-P_{r e f}(t)\right|\right) d t}{\int_{0}^{T} P_{P T O, r e f}(t) d t}\right]
$$

\subsubsection{Non-Evolutionary NLPQL-Based Optimisation}

The NLPQL algorithm was a local optimiser and has the advantages of fast convergence and high-stability [42]. In several studies, the NLPQL-based optimisation was applied to solve and optimise various non-linear problems during the design stage [42-45]. Figure 7A shows the flowchart of the NLPQL-based optimisation technique. Initially, the NLPQL-based optimisation process was started by randomly generating the guest point of each study parameter $\left(d_{p}, d_{r}, p_{0, H P A}, V_{c a p, H P A}, p_{0, L P A}, V_{c a p, L P A}, D_{H M}\right)$. Then, in the first iteration, the generated random guest point was chosen for each study parameter, and the HPTO model was then evaluated based on the objective function in Equation (22). The linear search calculation method was then implemented in order to determine the convergence satisfaction of the objective function. As presented in Figure 7A, the new iteration will be started if the objective function does not meet the convergence criterion. A new iteration was initially started to determine the new search direction and step size using the sequential quadratic programming (SQP) method. Then, the variables for each study parameters were determined based on the new search direction and step size. Finally, the Hessian approximation was updated by the modified BFGS-formula, as described in [42]. The parameters setting of the NLPQL-based optimisation is listed in Table 4. This process was repeated until the NLPQL algorithm met the termination accuracy.

Table 4. Parameters setting of NLPQL.

\begin{tabular}{cc}
\hline Setting & Value \\
\hline Maximum number of function evaluations & 7 \\
Maximum number of iterations & 100 \\
Step size for finite difference step & 0.001 \\
Final accuracy & 0.0001 \\
\hline
\end{tabular}

\subsubsection{Evolutionary GA-Based Optimisation}

In contrast to the NLPQL, GA was an evolutionary algorithm that was inspired by the natural evolution process. GA has been effectively applied to a wide range of realworld problems. In this algorithm, the variables of the optimisation problem were coded in chromosomes. Figure 7B presents the flowchart of the GA pseudo-code. The GAbased optimisation process was initially started by randomly generating a population of chromosomes (study parameters: $d_{p}, d_{r}, p_{0, H P A}, V_{c a p, H P A}, p_{0, L P A}, V_{c a p, L P A}, D_{H M}$ ), as presented in Figure $7 \mathrm{~B}$. Thereafter, for the first iteration, the random values from the generated population were chosen for each study parameter. The HPTO model was then evaluated based on the objective function in Equation (22). The chromosomes of the population were then sorted according to the least cost or highest fitness. Some percentages of the best chromosomes were transferred directly to the next generation based on their merit. Then, three GA operators named as selection, crossover and mutation were implemented to manipulate the rest of the chromosomes for the next generation. During the selection rule, the parent's chromosome that contributed to the current population was selected for the next generation process. Then, pairs of selected parents were recombined by a crossover operator to produce new chromosomes. A mutation rule was then applied to the new 
chromosomes to avoid the GA converging to the local optimum. Finally, this process was iterated until the satisfactory fitness level was reached. The parameters setting of GA was gathered in Table 5.

Table 5. Parameters setting of GA.

\begin{tabular}{cc}
\hline Setting & Value \\
\hline Population size & 50 \\
Reproduction ratio (\%) & 80 \\
Maximum number of generations & 100 \\
Mutation probability (\%) & 10 \\
Mutation amplitude & 0.1 \\
Seed & 1 \\
Final accuracy & 0.0001 \\
\hline
\end{tabular}

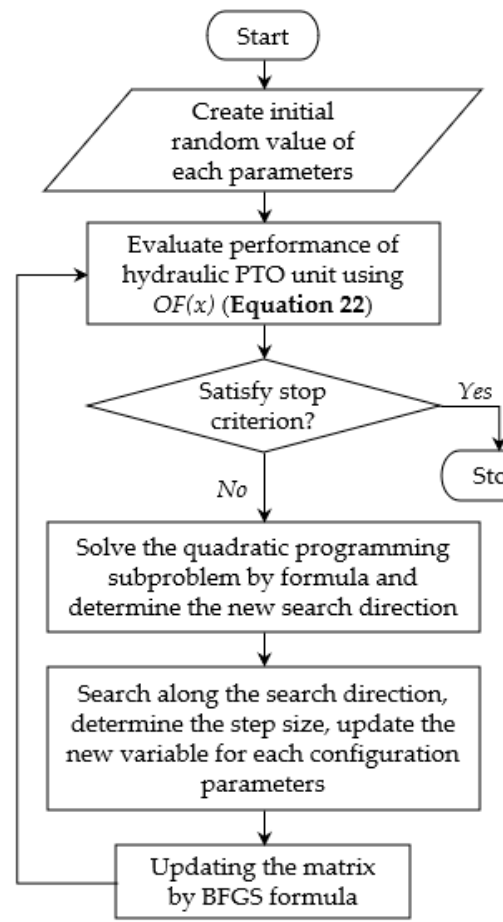

(A)

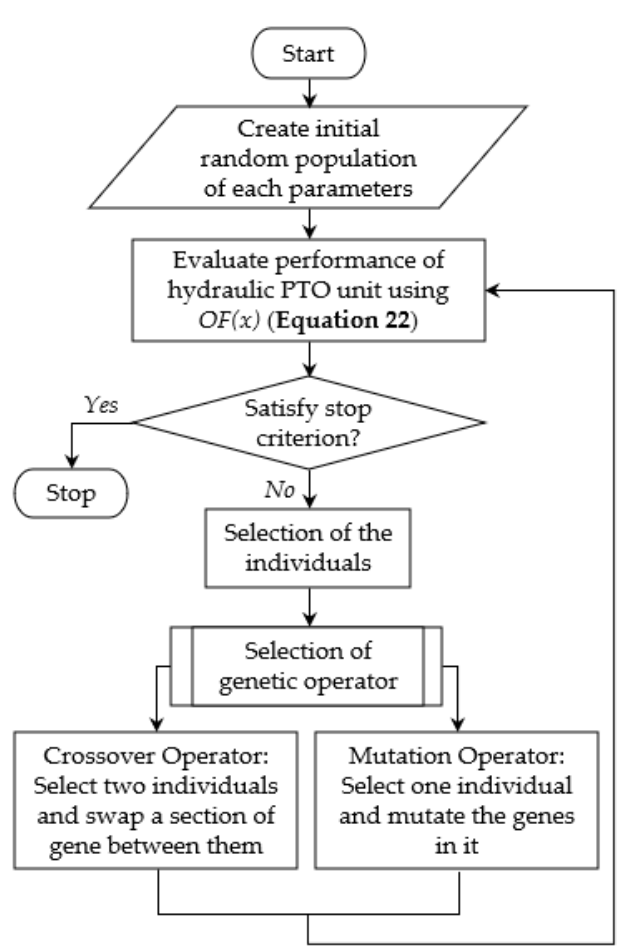

(B)

Figure 7. Optimisation procedures using (A) Non-Linear Programming by Quadratic Lagrangian (NLPQL) and (B) Genetic Algorithm (GA).

\section{Results and Discussion}

\subsection{Comparisons between NLPQL and GA Optimisation of HPTO Unit}

In order to evaluate the best optimisation approaches for the HPTO unit, a critical comparison analysis was performed. The comparison in terms of the final objective function, the best-estimated parameter values and the HPTO unit's performance were considered.

\subsubsection{Chronological Variation of the Objective Function and Parameters Variables}

Figures 8 and 9 depicted the chronological variation of the objective function and parameters variables with respect to the number of generations of the optimisation processes done by NLPQL and GA operators. The red vertical line in both figures indicated the optimisation process's termination at the lowest objective function value. The lowest objective function value was of interest for optimisation purposes in a feasible solution framework. Both of the optimisation processes were terminated after the algorithms 
met the optimum point, which was determined based on the termination criterion (final accuracy), as previously mentioned in Tables 4 and 5 .


Figure 8. Chronological variation of (A) objective function, $(\mathbf{B})$ diameter of piston and rod, $(\mathbf{C})$ pre-charge gas pressure and capacity of HPA, (D) pre-charge gas pressure and capacity of LPA, and (E) displacement of HM for NLPQL algorithm. 

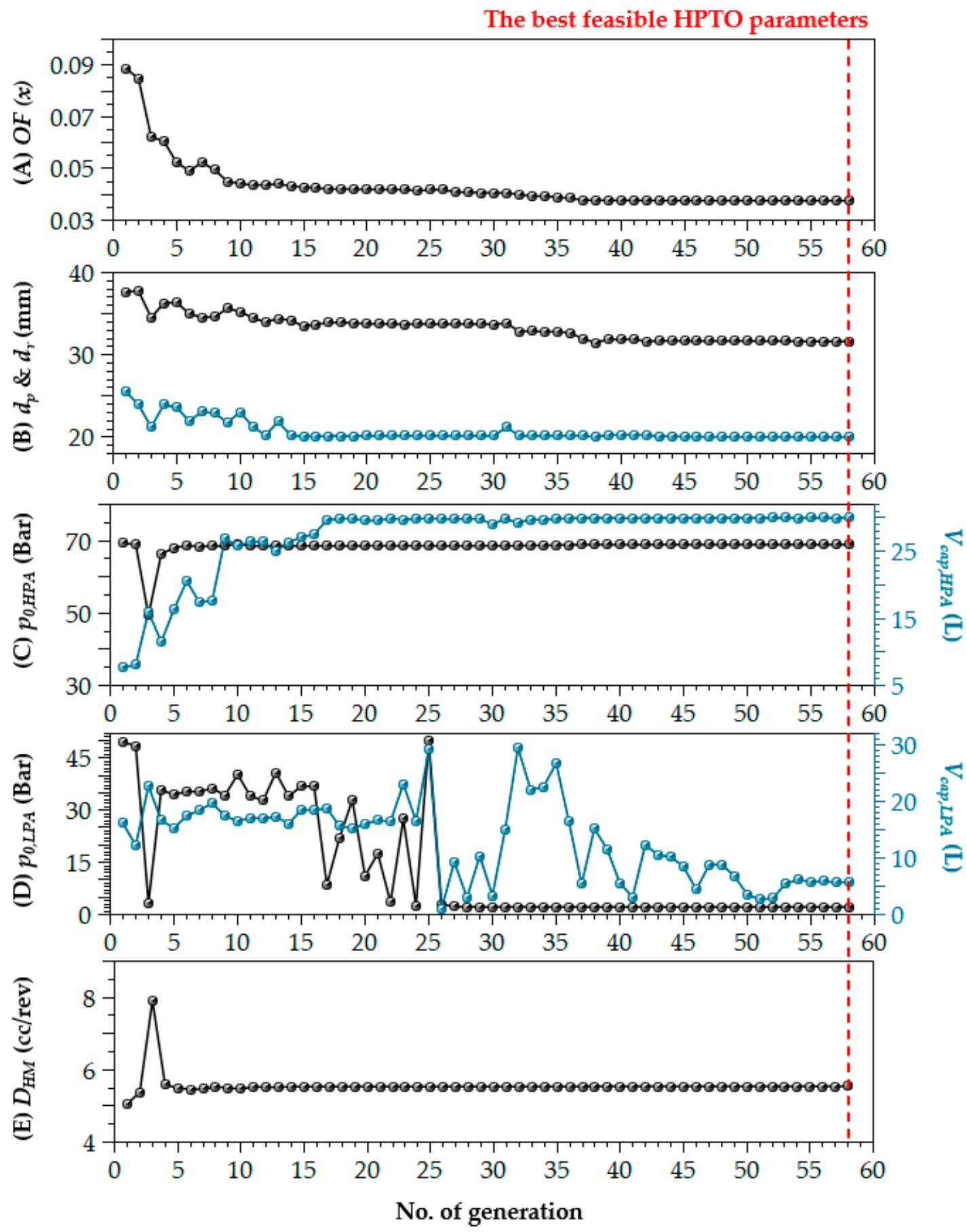

Figure 9. Chronological variation of $(\mathbf{A})$ objective function, $(\mathbf{B})$ diameter of piston and rod, $(\mathbf{C})$ pre-charge gas pressure and capacity of HPA, (D) pre-charge gas pressure and capacity of LPA, and (E) displacement of HM for GA algorithm.

Figure $8 \mathrm{~A}$ showed that the estimation process of the best configuration parameters was completed after the 22 number of iterations since the NLPQL operator had satisfied its accuracy requirement. The overall simulation-optimisation process using the NLPQL algorithm was carried out for $3237 \mathrm{~s}$ (approximately $53 \mathrm{~m} 57 \mathrm{~s}$ ). As shown in the figure, the lowest objective function value at 22 iterations was obtained at 0.0492 . Meanwhile, 56 numbers of iterations were needed to find the optimum case by the GA operator, as exhibited in Figure 9A. A complete simulation-optimisation process by the GA operator was performed for $7 \mathrm{~h}$ and $32 \mathrm{~min}$. The lowest objective function was obtained equal to 0.0375 , as illustrated in Figure 9A. Besides that, Figure 8B-E showed the chronological variation of the HPTO parameters throughout the optimisation process by the NLPQL algorithm. From 
these figures, the HPTO parameters seemed to approach the optimum conditions starting from 14 number of iterations. On the other hand, for the GA optimisation, Figure 9B-E showed that some of the HPTO parameters reached the best condition after 5 iterations.

In summary, the comparison of the chronological results of both optimisation approaches in Figure 8, and Figure 9 found that the optimisation using the NLPQL algorithm was much faster than the GA optimisation case. The reason was that since the NLPQL was the local optimisation approach, this algorithm depended on the initial point of each HPTO parameter. As reported in [42], the numerical test showed that different initial points required different time consumed and would give different optimal results. In contrast to the NLPQL algorithm, since the GA is a global algorithm, it takes more time in its exploration and exploitation processes that consider more points in search space in order to find the optimum condition. Thus, it returns more accurate and reliable results as depicted in Figure 9. In order to improve the performance of the NLPQL algorithm, the hybridisation of the NLPQL algorithm with the other global optimisation operators can be considered, as presented in [46]. In [46], the optimal starting points of the NLPQL algorithm were set by GA, and better optimum results have turned up.

\subsubsection{Best Estimated Parameters}

Table 6 presents the best configuration parameters sets of the HPTO unit that were successfully estimated using NLPQL and GA optimisation approaches. As shown in the table, the $d_{p}$ and $d_{r}$ parameters of the hydraulic cylinder were estimated at $3 \%$ and $12.8 \%$ smaller than their initial values for the NLPQL case, which equaled to $34.9 \mathrm{~mm}$ and 21.8 $\mathrm{mm}$, respectively. For the GA case, the $d_{p}$ and $d_{r}$ were estimated closely to their minimum constraints, which equal to $37.6 \mathrm{~mm}$ and $10 \mathrm{~mm}$. Apart from that, the data in Table 6 reported that the best-estimated values of the $p_{0, H P A}$, and $V_{\text {cap,HPA }}$ from the NLPQL, and GA optimisation were significantly different from their initial condition. The optimal value of $p_{0, H P A}$ was estimated larger than its initial value for both cases. While, for the $V_{\text {cap }, H P A}$, Table 6 clearly shows that the best values of $V_{\text {cap }, H P A}$ were estimated $65 \%$ lower and $275 \%$ larger than its initial value for the NLPQL and GA cases. For the $p_{0, L P A}$ and $V_{c a p, L P A}$, the best-estimated values were not too significantly different from their initial values for both cases. Furthermore, it can be found in Table 6 that the best values of $D_{H M}$ were significantly different between both optimisation cases. The result from the table shows that the GA operator successfully estimated a smaller value of $D_{H M}$ compared to the NLPQL case.

In summary, based on the comparison of best configuration parameters estimated from both optimisation approaches, a few preliminary conclusions in terms of physical size, cost of the HPTO unit and others can be drawn. Practically, the physical size, weight and cost of the HPTO unit depend on its configuration parameters. Based on the results in Table 6, it can be preliminarily concluded that the physical size and weight of the HPTO unit for the NLPQL approach were much smaller than the GA approach case. This was due to the larger capacity of HPA as estimated by the GA approach. The physical size and weight of the HPTO unit were vital to being reduced since they can influence the complete design of the WECs, as reported in [13]. Moreover, the configuration parameters also influenced the total cost of the HPTO unit. As reported in [10], the hydraulic accumulator and the hydraulic motor were the most expensive HPTO unit components. Thus, from Table 6, it can be concluded that the overall cost of the WECs from the NLPQL optimisation approach was much lower than the GA case. 
Table 6. Best configuration parameters from NLPQL and GA parameter estimation approaches.

\begin{tabular}{cccc}
\hline Parameter (Unit) & Non-Optimal Case & \multicolumn{2}{c}{ Optimal Case by } \\
\cline { 3 - 4 } & & NLPQL & GA \\
\hline Hydraulic cylinder & 36 & 34.9 & 31.6 \\
Diameter of piston, $d_{p}(\mathrm{~mm})$ & 25 & 21.8 & 20.0 \\
Diameter of piston rod, $d_{r}(\mathrm{~mm})$ & & 46.9 & 68.9 \\
HP accumulator & 40 & 2.8 & 30.0 \\
Pre-charge gas pressure, $p_{0, H P A}($ bar $)$ & 8 & 3.2 & 2.2 \\
Volume capacity, $V_{c a p, H P A}(\mathrm{~L})$ & 5 & 4.0 & 5.8 \\
LP accumulator & 2 & & \\
Pre-charge gas pressure, $p_{0, L P A}($ bar $)$ & & 8.4 & 5.5 \\
Volume capacity, $V_{\text {cap, } L P A}(\mathrm{~L})$ & 8 & & \\
$\quad$ Hydraulic motor & & & \\
Displacement, $D_{H M}(\mathrm{cc} / \mathrm{rev})$ & &
\end{tabular}

\subsubsection{Operational Behaviour of the HPTO Unit}

Table 7 compares the operational behaviour of the HPTO unit for the non-optimal, NLPQL-optimal, and GA-optimal cases. By comparing the data in Table 7 and Appendix A, the HPTO unit's operations were satisfied with its operational constraints for all cases. As reported in Table 7, the overall operating pressure of the HPTO unit increased for both optimal cases. For example, the operating pressures of the hydraulic cylinder chambers for the NLPQL-optimal case increased by $8.6 \%$ (side A) and $8.8 \%$ (side B). While, for the GAoptimal case, the operating pressures of the hydraulic cylinder increased by $56.6 \%$ (side A) and $56.8 \%$ (side B) from the non-optimal case, respectively. Besides that, the pressures in the HPA for both cases also increased up to $10.1 \%$ and $60.8 \%$, respectively. The hydraulic motor pressure also significantly increased by $9.4 \%$ and $60 \%$ for both cases, up to 47.5 bar and 69.8 bar.

Table 7. Comparison of the operational behaviour of the HPTO unit for non-optimal, NLPQL-optimal, and GA-optimal cases.

\begin{tabular}{ccccc}
\hline Descriptions (Unit) & & \multirow{2}{*}{ Non-Optimal Case } & \multicolumn{2}{c}{ Optimal Case by } \\
\cline { 5 - 5 } & & & NLPQL & GA \\
\hline Hydraulic cylinder & & & & \\
Max. operating pressure, (bar) & Side A & 46.48 & 50.5 & 72.8 \\
& Side B & 46.40 & 50.5 & 72.8 \\
Max. operating flow rate, (L/min) & Side A (In) & 2.75 & 3.49 & 2.71 \\
& Side A (Out) & 4.73 & 4.29 & 4.05 \\
HP accumulator & Side B (In) & 2.10 & 2.08 & 2.33 \\
Max. operating pressure, (bar) & Side B (Out) & 2.07 & 2.23 & 2.25 \\
Max. operating flow rate, (L/min) & & & & \\
LP accumulator & In & 43.4 & 47.8 & 69.8 \\
Max. operating pressure, (bar) & Out & 3.78 & 3.23 & 3.06 \\
Max. operating flow rate, (L/min) & & 1.36 & 1.66 & 1.10 \\
Hydraulic motor & In & & & \\
Max. operating pressure, (bar) & Out & 5.05 & 3.25 & 2.61 \\
& Inlet & 1.28 & 1.66 & 1.09 \\
Max. operating flow rate, (L/min) & Outlet & 1.30 & 1.82 & 0 \\
Max. operating speed, (rpm) & & 43.4 & 47.5 & 69.8 \\
Max. operating torque, (Nm) & & 5.03 & 3.25 & 2.63 \\
\hline & & 5.03 & 1.67 & 1.10 \\
\hline & & 174 & 202 & 204 \\
\hline & & 5.24 & 6.04 & 6.05 \\
\hline
\end{tabular}


The increasing pressure in the HPTO unit significantly increased the speed and torque of the hydraulic motor. As depicted in Table 7, the hydraulic motor speed and torque increased to its rated $(200 \mathrm{rpm}, 6 \mathrm{Nm})$ for both cases. In short, the results in Table 7 clearly show that the operational speed and torque of the hydraulic were influenced by the pressure of the other components in the HPTO unit. Thus, the presented results in Table 7 proved that the optimisation process by NLPQL and GA were highly effective in estimating the best component parameters of the HPTO unit.

\subsubsection{Performance of the WECs}

Technically, the force of the HPTO unit was directly proportional to its operational pressure $[15,37]$. Since the HPTO unit's pressure significantly increased, the HPTO force applied to the WEC device also increased, as depicted in Figure 10. Comparing Figure 10 with Figure 6B showed that the HPTO force applied to the WEC obviously increased for both cases. As depicted in Figure 10A, the HPTO forces applied to the WEC for the NLPQL case can be reached up to $1.65 \mathrm{kN}$ (upward) and $0.78 \mathrm{kN}$ (downward). While, for the GA-optimal case, the HPTO forces applied to the WEC can be reached up to $2.3 \mathrm{kN}$ (upward) and $1.2 \mathrm{kN}$ (downward), respectively. The results clearly showed that the overall HPTO force applied to the WEC device for the GA-optimal case was significantly larger than the HPTO force in the NLPQL case. This significant difference was attributed due to the larger pre-charge gas pressure and volume capacity of the HPA in the HPTO unit for the GA-optimal case, as depicted in Table 6. A larger pre-charge gas pressure required a more massive flow of high-pressure fluid [10]. In addition, from both figures, it can be seen that the HPTO forces applied to the WEC device during the upward movement were larger compared to the downward movement for both cases. This was due to the unsymmetrical double-acting hydraulic cylinder used in the HPTO unit. Since the hydraulic cylinder chambers were unsymmetrical, the fluid pressure in the chamber, which comprises a large effective piston area, was higher than the fluid pressure in the small effective area chamber, as clearly described in [10].
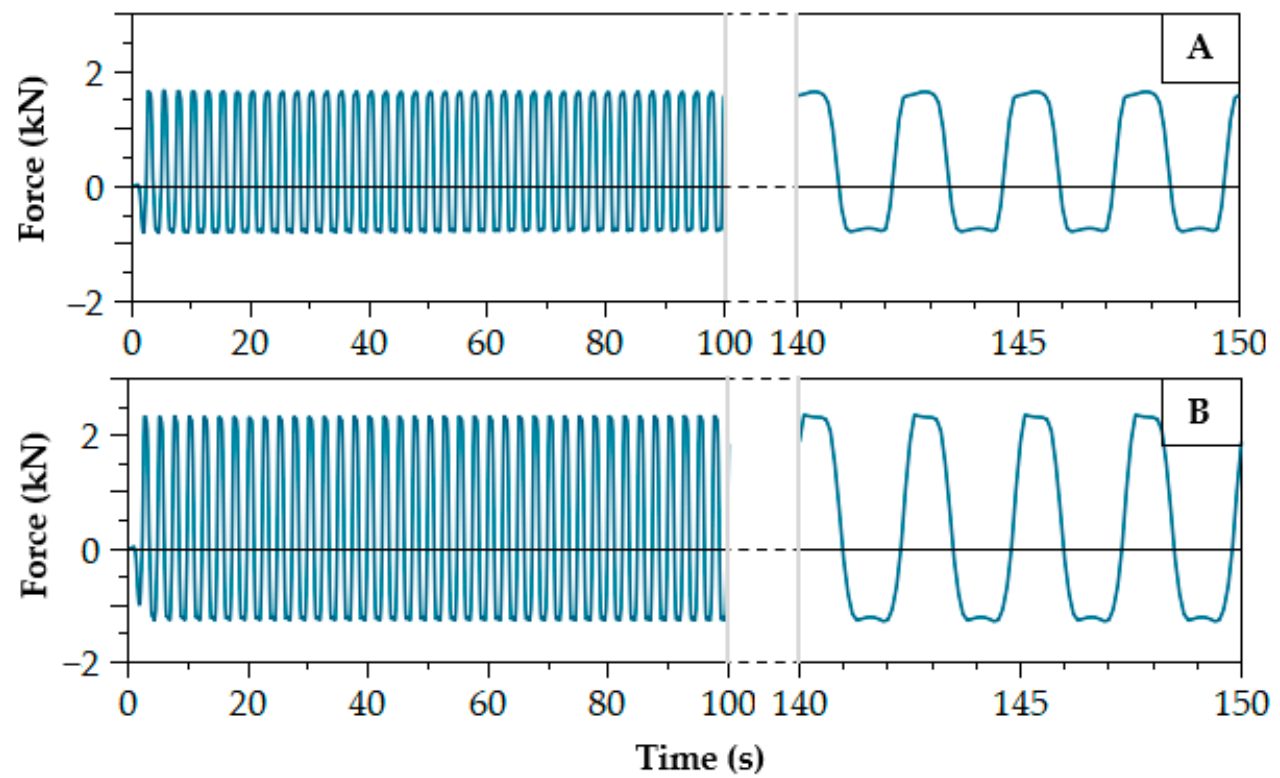

Figure 10. HPTO force applied to the WEC device $\left(H_{W}=0.8, T_{W}=2.5 \mathrm{~s}\right)$, (A) NLPQL and (B) GA cases.

Furthermore, the HPTO force's effect on the displacement of the WEC device and hydraulic cylinder piston can be seen in Figure 11. Figure 11A,B illustrated the displacement of the wave, WEC, and hydraulic cylinder piston during the HPTO unit operation for both optimal cases. In Figure 11A, it was depicted that the average displacements of the WEC device and hydraulic cylinder piston for the NLPQL-optimal were $77.5 \%$ and $19.3 \%$ of the average wave elevation. Meanwhile, for the GA-optimal case, the average displacement of 
the WEC device and hydraulic cylinder piston was $65 \%$ and $16 \%$ of average wave elevation. The comparison of the results in Figures 6A and 11 showed that the displacement of the WEC device and hydraulic cylinder piston was slightly reduced for the NLPQL-optimal and GA-optimal cases. The reduction was due to the larger HPTO force applied to the WEC device in both cases. In addition, the comparison of Figure 11A,B showed that the average displacement of the WEC device and hydraulic cylinder piston for GA-optimal was less than the NLPQL-optimal case.
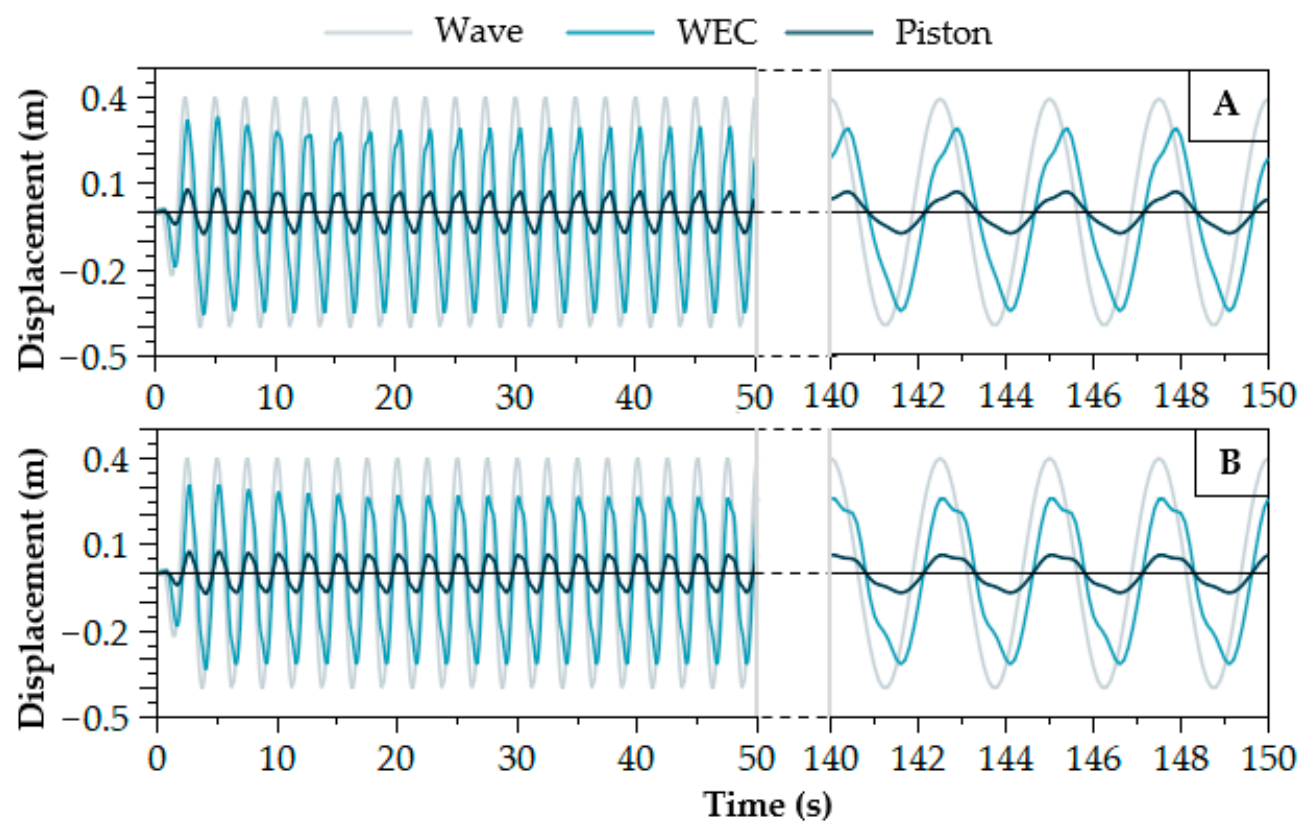

Figure 11. Displacement of the wave, WEC, and piston for three different cases $\left(H_{W}=0.8, T_{W}=2.5 \mathrm{~s}\right)$, (A) NLPQL and (B) GA cases.

Apart from that, Figure 12 illustrated the comparison of the electrical power generation profiles of WECs for both optimal cases. Comparing the results in Figure 12 with Figure 6C, the overall electrical power generated from the HPTO unit optimised by NLPQL and GA approaches was successfully enhanced. For the non-optimal case, the electrical power profile in Figure 6C clearly indicated that the electrical power generated from the HPTO unit was lower than its rated capacity. Figure $6 \mathrm{C}$ showed the electrical power generated from the non-optimal HPTO was up to $71 \%(71 \mathrm{~W})$ of its rated capacity. In contrast to both optimal cases. From Figure 12, the result showed the electrical generated output of HPTO was close to its rated capacity. The average electrical power generated from the HPTO unit for the NLPQL-optimal and GA-optimal cases was calculated up to $96 \%$ (96 W) and 97\% $(97 \mathrm{~W})$ rated capacity, respectively. The comparison results in Figure 12 also showed that the electrical power generated from the HPTO unit of the GA-optimal case fluctuated less compared to the NLPQL-optimal case. This was due to the larger HPA used in the HPTO unit of the GA-optimal case. In addition, both of the optimal HPTO units reached their steady-state condition around $80 \mathrm{~s}$. 


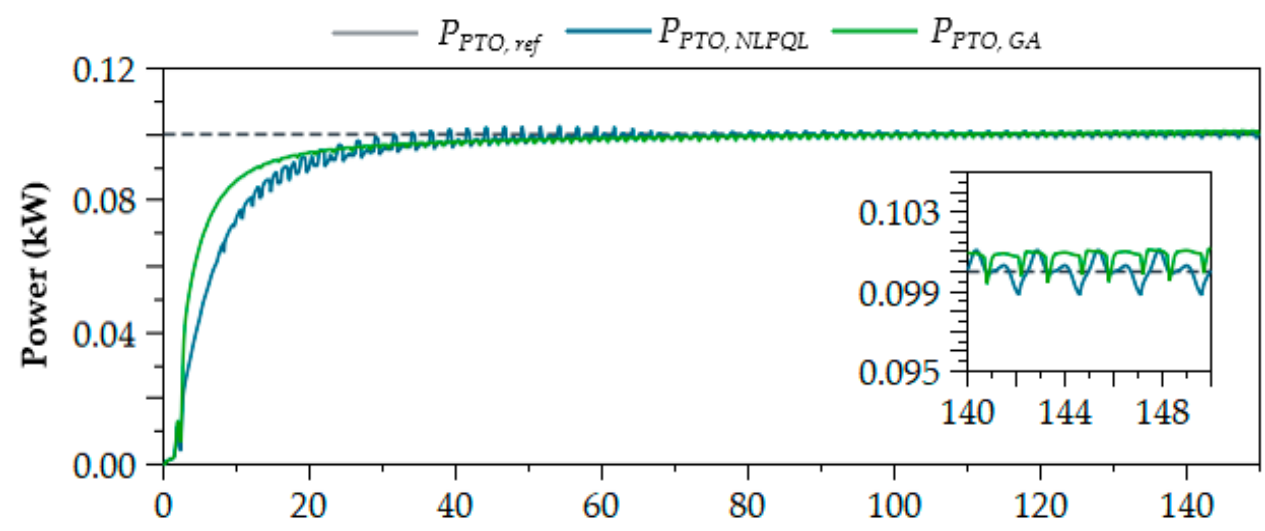

Figure 12. Comparison of electrical power generated from the best HPTO unit estimated by NLPQL and GA optimisations $\left(H_{W}=0.8, T_{W}=2.5 \mathrm{~s}\right)$.

\subsection{Evaluations of Optimal WECs Using Irregular Wave Data}

The optimal HPTO units obtained from the optimisation processes were evaluated using irregular wave elevation input in order to evaluate their performance in generating the electricity in irregular wave circumstances. The results in Figure 13 provided the hydraulic cylinder piston responses for both cases. The figure showed that the displacement of the hydraulic cylinder piston for GA-optimal was smaller than the NLPQL-optimal case. This was due to the different pressures in the hydraulic cylinder chambers, as shown in Figure 14. Figure 14A showed that the reciprocating motions of the piston for the NLQPL case produced high-pressure liquid in both hydraulic cylinder chambers that reached up to 54 Bar. At the same time, the pressure of the hydraulic cylinder chamber for the GA case reached up to 75 Bar. The pressure difference for both cases was due to the difference in the HPTO unit's parameter design.

The high-pressure liquid produced in the hydraulic cylinder chamber then flowed to HPA and hydraulic motor. The HPA was used as liquid energy storage to smooth out pressure fluctuation in the HPTO unit. Thus, the liquid's pressure, which exceeded the HPA pre-charge pressure setting, was accumulated in the HPA ballast. In contrast, the HPA released the high-pressure liquid stored in its ballast when the HPTO system's pressure was lower than its pre-charge pressure setting. Figure 15 showed the pressure of the HPA for both optimal cases. For both cases, the pre-charge pressures of HPA were set to 46.9 Bar and 68.9 Bar, as previously given in Table 6. In Figure 15A, the pressure of the HPA reached up to $49 \mathrm{Bar}$, which was $4.5 \%$ higher than its pre-charge pressure setting several times. For the GA case, the highest pressure of the HPA can be reached up to $69.01 \mathrm{Bar}$, which was $0.16 \%$ higher than its pre-charge pressure setting, as depicted in Figure 15B. The difference in the pressure variation rate of HPA in both cases was due to the different HPA volume capacity. As given in Table 6, the volume capacity of HPA for the GA-optimal case was larger than the NLPQL-optimal case. In addition, the comparison of results in Figure 15A,B showed that the high-pressure liquid accumulation was more often for the GA-optimal case. This was due to a larger volume capacity of HPA used in the HPTO unit.

The smoothing effects of the HPA unit on the pressure in the HPTO unit for both optimal cases can be clearly seen in Figure 16. Figure 16A,B showed the smoothed pressure of the hydraulic motor for both cases. The comparison results in Figure 16A,B showed that the smoothing effect of the hydraulic motor pressure for the GA-optimal case was higher than the NLPQL-optimal case. It can be seen from the figures, the pressure of the hydraulic motor fluctuated less for the GA-optimal case compared to the NLPQLoptimal case. However, at the initial state of both cases, the hydraulic motor's pressure was more fluctuating due to insufficient energy stored in the HPA, as depicted in Figure 15. In addition, Figure 17 illustrated the comparison of the hydraulic motor speed for both cases. From the figure, the average speed of the hydraulic motor for the GA-optimal case was higher than the NLQPL-optimal case, which was $163 \mathrm{rpm}$ instead of $137 \mathrm{rpm}$. 


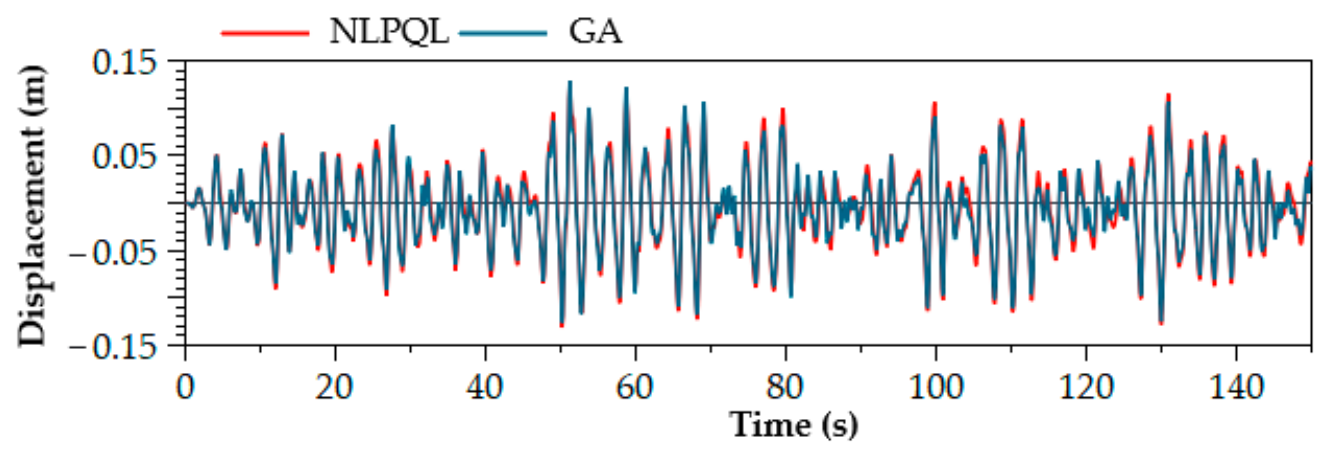

Figure 13. Displacement of hydraulic cylinder piston of HPTO unit $\left(H_{W}=0.8, T_{W}=2.5 \mathrm{~s}\right)$.

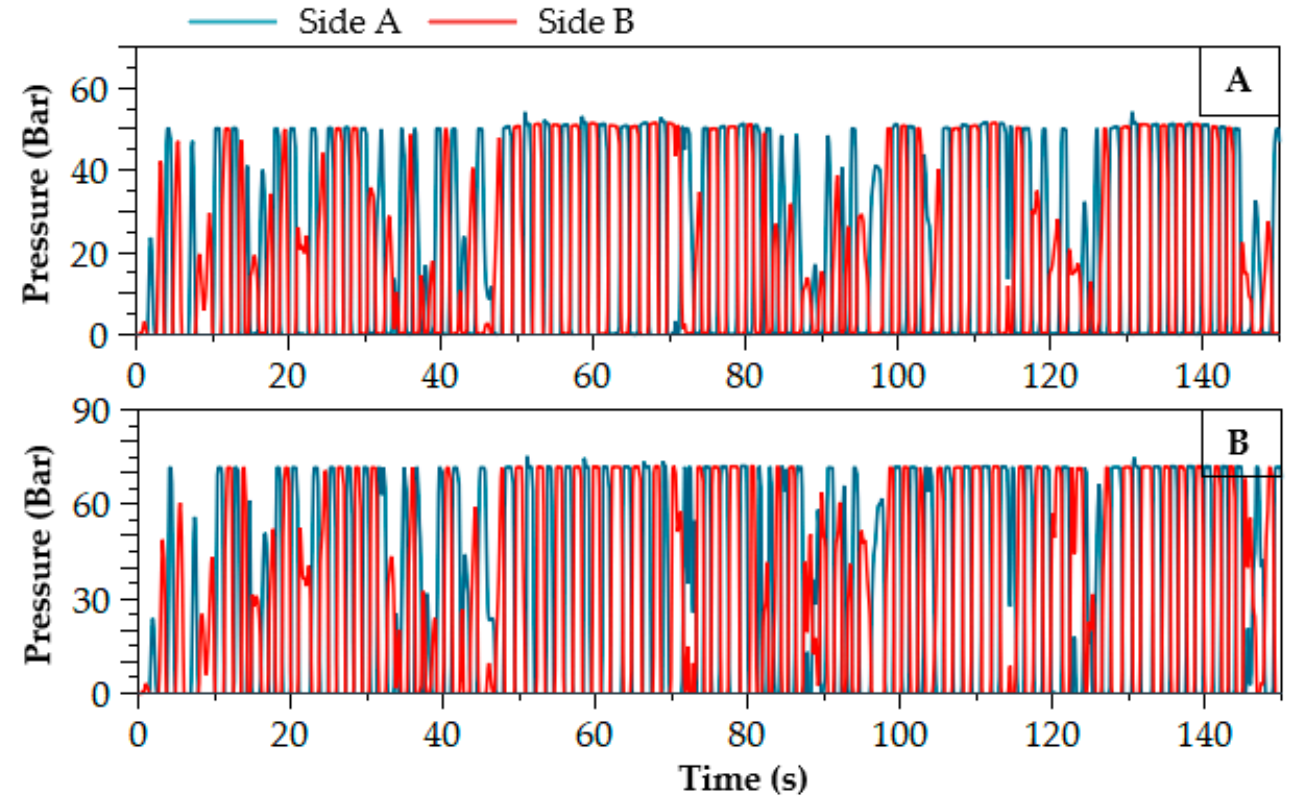

Figure 14. The pressure of the hydraulic cylinder chamber of HPTO unit $\left(H_{W}=0.8, T_{W}=2.5 \mathrm{~s}\right)$, (A) NLPQL and (B) GA cases.
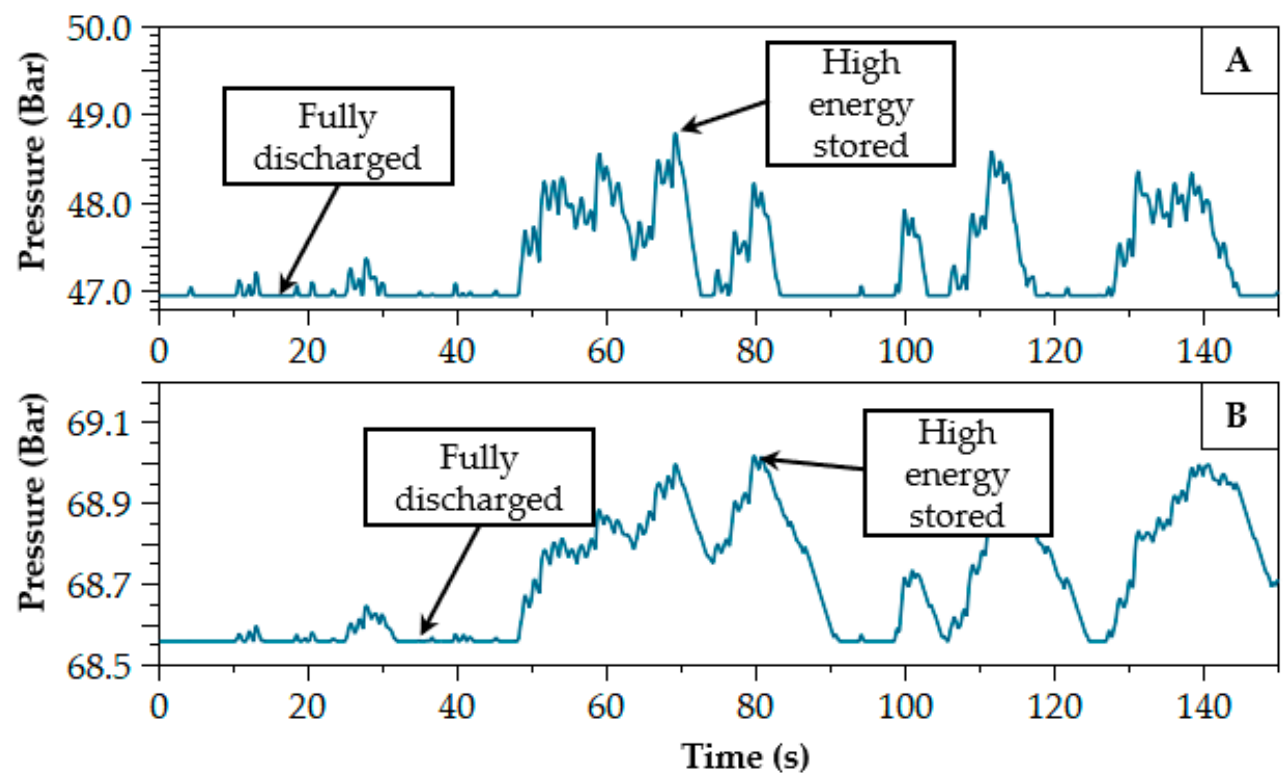

Figure 15. Pressure of high-pressure accumulator of HPTO unit $\left(H_{W}=0.8, T_{W}=2.5 \mathrm{~s}\right),(\mathbf{A}) \mathrm{NLPQL}$ and (B) GA cases. 




Figure 16. The pressure of hydraulic motor of HPTO unit $\left(H_{W}=0.8, T_{W}=2.5 \mathrm{~s}\right),(\mathrm{A})$ NLPQL and (B) GA cases.
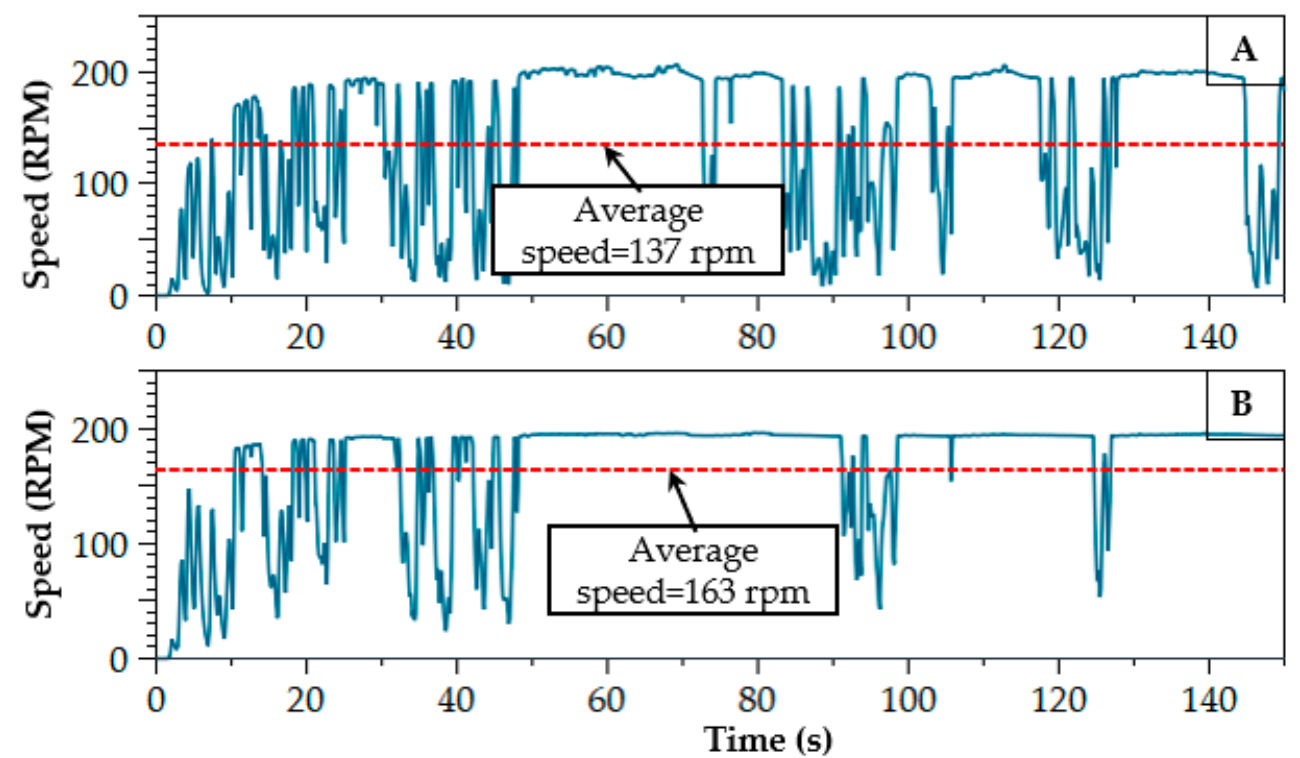

Figure 17. Speed of hydraulic motor of HPTO unit $\left(H_{W}=0.8, T_{W}=2.5 \mathrm{~s}\right)$, (A) NLPQL and (B) GA cases.

Figure 18A-C presented the electrical power profiles of the HPTO unit for the nonoptimal, NLPQL-optimal and GA-optimal cases. For the non-optimal case, the average electrical power generated from the PMSG generator in the HPTO unit was equal to $55 \mathrm{~W}$, which was only $55 \%$ of its rated capacity, as shown in Figure 18A. For this case, the highest electrical power that was generated only reached up to $71 \mathrm{~W}$. This was significantly different for the cases of the optimal HPTO unit optimised by NLPQL and GA approaches. It can be seen in Figure 18B,C, both optimal HPTO units capable of generating electricity of up to an average of $62 \mathrm{~W}$ and $77 \mathrm{~W}$, which was $62 \%$ and $77 \%$ of its rated capacity, respectively. 

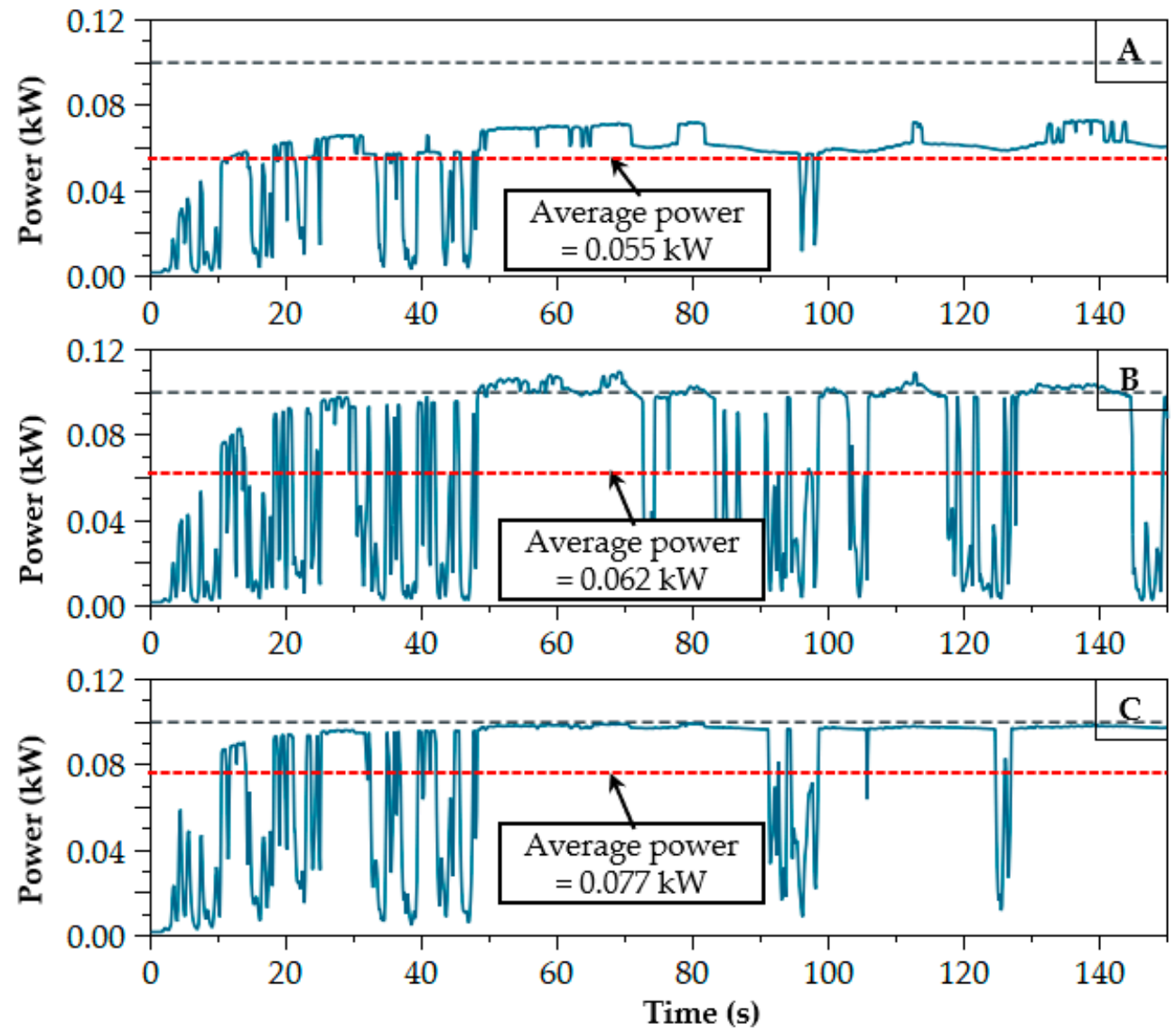

Figure 18. Comparison of electrical power generated from the best HPTO unit in irregular wave condition $\left(H_{W}=0.8, T_{W}=2.5 \mathrm{~s}\right)$, (A) Non-optimal, (B) NLPQL-optimal, and (C) GA-optimal cases.

\section{Conclusions}

A comprehensive study was conducted to estimate the configuration parameters of the HPTO unit for a wave energy conversion device using a non-evolutionary NLPQL and evolutionary genetic algorithm. Seven important configuration parameters of the HPTO unit were considered in this optimisation study. The simulation-optimisation of HPTO model parameters was performed using MATLAB ${ }^{\circledR \circledR} /$ Simulink software. The optimisation function problem was designed to maximise the output power generated from the HPTO unit. The optimal HPTO unit was then evaluated using irregular wave input to evaluate its performance in irregular circumstances. From the simulation studies, the key results can be listed as follows:

- The simulation-optimisation using the NLPQL algorithm was completed after the 22 number of iterations with the duration of $3237 \mathrm{~s}$ (approximately $53 \mathrm{~m} 57 \mathrm{~s}$ ) after the NLPQL operator had satisfied its accuracy requirement. Importantly, the overall performance of HPTO has significantly improved up to $96 \%$ in regular wave conditions.

- The simulation-optimisation duration using the GA technique is longer than the NLPQL approach, which was completed after $7 \mathrm{~h}$ and $32 \mathrm{~min}$. However, the overall performance of HPTO has significantly improved up to $97 \%$ in regular wave conditions.

- The HPTO unit estimated by the NLPQL approach is much smaller in terms of size, weight and cost compared to the GA approach. Thus, the HPTO unit's cost estimated by NLPQL is cheaper than the HPTO unit cost estimated by the GA approach.

- The results show that both optimal HPTO units can generate electricity up to $62 \%$ and $77 \%$ of rated capacity in irregular wave circumstances.

- In conclusion, both of the optimisation approaches were effective in determining the optimal parameters of the HPTO unit. For the sake of quickness, the NLPQL 
approach is more relevant. While, for the sake of effectiveness, the GA approach is more recommended.

The simulation-optimisation framework presented may help the engineers and researchers of WECs to design a reliable and high-efficiency HPTO unit for wave energy converter devices. It is suggested that further researches should be conducted in the following areas:

- Further experimental validation of the best estimated HPTO unit is needed to verify the accuracy of the developed model simulation.

- The simulation-optimisation of the HPTO unit using other types of the optimisation algorithm, such as Particle Swarm Optimization, Gravitational Search Algorithm, et cetera, needs to be explored to achieve a good trade-off between cost and performance.

- The simulation-optimisation using other software types, such as Simcenter Amesim software invented by Siemens, is highly recommended.

Author Contributions: M.A.J., conceptualisation, methodology, software, data curation, analysis, writing-original draft; M.Z.I., writing—review and editing and supervision, project administration, funding acquisition; M.Z.D., conceptualisation, methodology, writing-review and editing and supervision; Z.M.Y., software, data curation, analysis and writing-original draft; A.A. data curation, analysis and writing-review and editing. All authors have read and agreed to the published version of the manuscript.

Funding: This project was funded by the Ministry of Higher Education (MOHE) under Fundamental Research Grant Scheme (FRGS/1/2019/TK07/UMT/01/1).

Acknowledgments: The authors would like to thank the Ministry of Higher Education (MOHE) and Universiti Malaysia Terengganu (UMT) for financial support for this research.

Conflicts of Interest: The authors declare no conflict of interest.

$\begin{array}{ll}\text { Abbreviations } \\ \text { ACO } & \text { Ant Colony Optimization } \\ \text { CFD } & \text { Computational Fluid Dynamics } \\ \text { CV } & \text { Check Valve } \\ \text { GA } & \text { Genetic Algorithm } \\ \text { GSA } & \text { Gravitational Search Algorithm } \\ \text { HM } & \text { Hydraulic Motor } \\ \text { HPA } & \text { High-Pressure Accumulator } \\ \text { HPTO } & \text { Hydraulic Power Take-Off } \\ \text { JONSWAP } & \text { Joint North Sea Wave Observation Project } \\ \text { LPA } & \text { Low-Pressure Accumulator } \\ \text { NLPQL } & \text { Non-Linear Programming by Quadratic Lagrangian } \\ \text { OF } & \text { Objective Function } \\ \text { PMSG } & \text { Permanent Magnet Synchronous Generator } \\ \text { PSO } & \text { Particle Swarm Optimization } \\ \text { PTO } & \text { Power Take-Off } \\ \text { SOC } & \text { State-Of-Charge } \\ \text { SQP } & \text { Sequential Quadratic Programming } \\ \text { TS } & \text { Tabu Search } \\ \text { WAB } & \text { Wave-Activated-Body } \\ \text { WEC } & \text { Wave Energy Converter } \\ \text { WECs } & \text { Wave Energy Converters } \\ & \end{array}$




\section{Appendix A}

Table A1. Specifications of hydraulic components from Parker Hannifin Manufacturer.

\begin{tabular}{|c|c|c|c|}
\hline \multirow{2}{*}{ HPTO Component (Unit) } & \multicolumn{2}{|c|}{ Ranges } & \multirow{2}{*}{ Ref. } \\
\hline & Minimum & Maximum & \\
\hline Hydraulic cylinder a & & & [47] \\
\hline Available piston diameter, $(\mathrm{mm})$ & 30 & 203 & \\
\hline Available rod diameter, $(\mathrm{mm})$ & 10 & 140 & \\
\hline Operating pressure, (bar) & 0 & 207 & \\
\hline Operating flow rate, $(\mathrm{L} / \mathrm{min})$ & 0 & 900 & \\
\hline HP accumulator $b$ & & & [48] \\
\hline Available nominal volume, (L) & 0.2 & 57 & \\
\hline Operating pressure, (bar) & 0 & 690 & \\
\hline Operating flow rate, $(\mathrm{L} / \mathrm{min})$ & 0 & 900 & \\
\hline LP accumulator ${ }^{c}$ & & & [49] \\
\hline Available nominal volume, (L) & 0 & 565 & \\
\hline Operating pressure, (bar) & 0 & 80 & \\
\hline Operating flow rate, $(\mathrm{L} / \mathrm{min})$ & 0 & 3000 & \\
\hline Hydraulic motor d & & & {$[50]$} \\
\hline Available motor displacement, (cc/rev) & 20 & 23,034 & \\
\hline Operating pressure, (bar) & 0 & 420 & \\
\hline Operating speed, (rpm) & 0 & 1000 & \\
\hline Operating flow rate, $(\mathrm{L} / \mathrm{min})$ & 0 & 200 & \\
\hline Operating torque, $(\mathrm{Nm})$ & 0 & 1428 & \\
\hline
\end{tabular}

${ }^{a}$ Heavy Duty Roundline Welded Series, ${ }^{b}$ High-Pressure Bladder Accumulator Series, ${ }^{c}$ Low-Pressure Bladder Accumulator Series, ${ }^{\mathrm{d}}$ High Torque Radial Piston Motors Series.

\section{References}

1. Sang, Y.; Karayaka, H.B.; Yan, Y.; Yilmaz, N.; Souders, D. Ocean (Marine) Energy. In Comprehensive Energy Systems; Elsevier: Amsterdam, The Netherlands, 2018; Volumes 1-5, pp. 733-769, ISBN 9780128095973.

2. Mustapa, M.A.; Yaakob, O.B.; Ahmed, Y.M.; Rheem, C.K.; Koh, K.K.; Adnan, F.A. Wave energy device and breakwater integration: A review. Renew. Sustain. Energy Rev. 2017, 77, 43-58. [CrossRef]

3. de Falcão, A.F.O. Wave energy utilization: A review of the technologies. Renew. Sustain. Energy Rev. 2010, 14, 899-918. [CrossRef]

4. Titah-Benbouzid, H.; Benbouzid, M. An up-to-date technologies review and evaluation of wave energy converters. Int. Rev. Electr. Eng. 2015, 10, 52-61. [CrossRef]

5. Rusu, E.; Onea, F. A review of the technologies for wave energy extraction. Clean Energy 2018, 2, 10-19. [CrossRef]

6. Al Shami, E.; Zhang, R.; Wang, X. Point absorber wave energy harvesters: A review of recent developments. Energies 2019, 12, 47. [CrossRef]

7. Têtu, A. Power Take-Off Systems for WECs; Springer: Cham, Switzerland, 2017; pp. 203-220.

8. Kukner, A.; Erselcan, İ.Ö. A review of power take-off systems employed in wave energy. J. Nav. Sci. Eng. 2014, 10, 32-44.

9. Gaspar, J.F.; Calvário, M.; Kamarlouei, M.; Guedes Soares, C. Power take-off concept for wave energy converters based on oil-hydraulic transformer units. Renew. Energy 2016, 86, 1232-1246. [CrossRef]

10. Jusoh, M.A.; Ibrahim, M.Z.; Daud, M.Z.; Albani, A.; Yusop, Z.M. Hydraulic power take-off concepts for wave energy conversion system: A review. Energies 2019, 12, 4510. [CrossRef]

11. Galván-Pozos, D.E.; Ocampo-Torres, F.J. Dynamic analysis of a six-degree of freedom wave energy converter based on the concept of the Stewart-Gough platform. Renew. Energy 2020, 146, 1051-1061. [CrossRef]

12. Penalba, M.; Davidson, J.; Windt, C.; Ringwood, J.V. A high-fidelity wave-to-wire simulation platform for wave energy converters: Coupled numerical wave tank and power take-off models. Appl. Energy 2018, 226, 655-669. [CrossRef]

13. Liu, C.; Yang, Q.; Bao, G. Influence of hydraulic power take-off unit parameters on power capture ability of a two-raft-type wave energy converter. Ocean Eng. 2018, 150, 69-80. [CrossRef]

14. Sheng, W.; Lewis, A. Power takeoff optimization for maximizing energy conversion of wave-activated bodies. IEEE J. Ocean. Eng. 2016, 41, 529-540. [CrossRef]

15. Cargo, C.J.; Hillis, A.J.; Plummer, A.R. Optimisation and control of a hydraulic power take-off unit for a wave energy converter in irregular waves. Proc. Inst. Mech. Eng. Part A J. Power Energy 2014, 228, 462-479. [CrossRef]

16. Brito, M.; Teixeira, L.; Canelas, R.B.; Ferreira, R.M.L.; Neves, M.G. Experimental and numerical studies of dynamic behaviors of a hydraulic power take-off cylinder using spectral representation method. J. Tribol. 2018, 140. [CrossRef]

17. Brito, M.; Ferreira, R.M.L.; Teixeira, L.; Neves, M.G.; Canelas, R.B. Experimental investigation on the power capture of an oscillating wave surge converter in unidirectional waves. Renew. Energy 2020, 151, 975-992. [CrossRef] 
18. Amaran, S.; Sahinidis, N.V.; Sharda, B.; Bury, S.J. Simulation optimization: A review of algorithms and applications. Ann. Oper. Res. 2016, 240, 351-380. [CrossRef]

19. Jusoh, M.A.; Daud, M.Z. Particle swarm optimisation-based optimal photovoltaic system of hourly output power dispatch using Lithium-ion batteries. J. Mech. Eng. Sci. 2017, 11, 2780-2793. [CrossRef]

20. Jusoh, M.A.; Daud, M.Z. Control strategy of a grid-connected photovoltaic with battery energy storage system for hourly power dispatch. Int. J. Power Electron. Drive Syst. 2017, 8, 1830-1840. [CrossRef]

21. Daud, M.Z.; Mohamed, A.; Hannan, M.A. An improved control method of battery energy storage system for hourly dispatch of photovoltaic power sources. Energy Convers. Manag. 2013, 73, 256-270. [CrossRef]

22. Daud, M.Z.; Mohamed, A.; Ibrahim, A.A.; Hannan, M.A. Heuristic optimization of state-of-charge feedback controller parameters for output power dispatch of hybrid photovoltaic/battery energy storage system. Meas. J. Int. Meas. Confed. 2014, 49, 15-25. [CrossRef]

23. Jusoh, M.A.; Daud, M.Z. Accurate battery model parameter identification using heuristic optimization. Int. J. Power Electron. Drive Syst. 2020, 11, 333-341. [CrossRef]

24. Giassi, M.; Göteman, M. Layout design of wave energy parks by a genetic algorithm. Ocean Eng. 2018, 154, 252-261. [CrossRef]

25. Sirigu, S.A.; Foglietta, L.; Giorgi, G.; Bonfanti, M.; Cervelli, G.; Bracco, G.; Mattiazzo, G. Techno-Economic optimisation for a wave energy converter via genetic algorithm. J. Mar. Sci. Eng. 2020, 8, 482. [CrossRef]

26. McCabe, A.P.; Aggidis, G.A.; Widden, M.B. Optimizing the shape of a surge-and-pitch wave energy collector using a genetic algorithm. Renew. Energy 2010, 35, 2767-2775. [CrossRef]

27. Calvário, M.; Gaspar, J.F.; Kamarlouei, M.; Hallak, T.S.; Guedes Soares, C. Oil-hydraulic power take-off concept for an oscillating wave surge converter. Renew. Energy 2020, 159, 1297-1309. [CrossRef]

28. Jusoh, M.A.; Ibrahim, M.Z.; Daud, M.Z.; Yusop, Z.M.; Albani, A.; Rahman, S.J.; Mohad, S. Parameters estimation of hydraulic power take-off system for wave energy conversion system using genetic algorithm. In Proceedings of the IOP Conference Series: Earth and Environmental Science; Institute of Physics Publishing: Bristol, UK, 2020; Volume 463, p. 12129.

29. Hansen, R.H.; Kramer, M.M.; Vidal, E.; Hansen, R.H.; Kramer, M.M.; Vidal, E. Discrete displacement hydraulic power take-off system for the wavestar wave energy converter. Energies 2013, 6, 4001-4044. [CrossRef]

30. Hansen, A.H.; Asmussen, M.F.; Bech, M.M. Model predictive control of a wave energy converter with discrete fluid power power take-off system. Energies 2018, 11, 635. [CrossRef]

31. Garcia-Rosa, P.B.; Cunha, J.P.V.S.; Lizarralde, F.; Estefen, S.F.; Costa, P.R. Efficiency optimization in a wave energy hyperbaric converter. In Proceedings of the 2009 International Conference on Clean Electrical Power, ICCEP 2009, Capri, Italy, 9-11 June 2009; pp. 68-75.

32. Estefen, S.F.; Esperança, P.D.T.; Ricarte, E.; Da Costa, P.R.; Pinheiro, M.M.; Clemente, C.H.P.; Franco, D.; Melo, E.; De Souza, J.A. Experimental and numerical studies of the wave energy hyperbaric device for electricity production. In Proceedings of the International Conference on Offshore Mechanics and Arctic Engineering-OMAE; American Society of Mechanical Engineers Digital Collection: New York, NY, USA, 2008; Volume 6, pp. 811-818.

33. Windt, C.; Davidson, J.; Ransley, E.J.; Greaves, D.; Jakobsen, M.; Kramer, M.; Ringwood, J.V. Validation of a CFD-based numerical wave tank model for the power production assessment of the wavestar ocean wave energy converter. Renew. Energy 2020, 146, 2499-2516. [CrossRef]

34. Ransley, E.J.; Greaves, D.M.; Raby, A.; Simmonds, D.; Jakobsen, M.M.; Kramer, M. RANS-VOF modelling of the Wavestar point absorber. Renew. Energy 2017, 109, 49-65. [CrossRef]

35. Gibraltar Project-Eco Wave Power. Available online: https://www.ecowavepower.com/gibraltar-project/ (accessed on 4 May 2019).

36. Penalba, M.; Sell, N.P.; Hillis, A.J.; Ringwood, J.V. Validating a wave-to-wire model for a wave energy converter-Part I: The hydraulic transmission system. Energies 2017, 10, 977. [CrossRef]

37. Cargo, C.J.; Plummer, A.R.; Hillis, A.J.; Schlotter, M. Determination of optimal parameters for a hydraulic power take-off unit of a wave energy converter in regular waves. Proc. Inst. Mech. Eng. Part A J. Power Energy 2012, 226, 98-111. [CrossRef]

38. Do, H.T.; Dang, T.D.; Ahn, K.K. A multi-point-absorber wave-energy converter for the stabilization of output power. Ocean Eng. 2018, 161, 337-349. [CrossRef]

39. Muzathik, A.M.; Wan Nik, W.B.; Samo, K.B.; Ibrahim, M.Z. Ocean wave measurement and wave climate prediction of Peninsular Malaysia. J. Phys. Sci. 2011, 22, 77-92.

40. Chen, Q.; Yue, X.; Geng, D.; Yan, D.; Jiang, W. Integrated characteristic curves of the constant-pressure hydraulic power take-off in wave energy conversion. Int. J. Electr. Power Energy Syst. 2020, 117, 105730. [CrossRef]

41. Jianan, X.; Tao, X. MPPT Control of Hydraulic Power Take-Off for Wave Energy Converter on Artificial Breakwater. J. Mar. Sci. Eng. 2019, 8, 304. [CrossRef]

42. Zhang, S.; Tezdogan, T.; Zhang, B.; Xu, L.; Lai, Y. Hull form optimisation in waves based on CFD technique. Ships Offshore Struct. 2018, 13, 149-164. [CrossRef]

43. Navid, A.; Khalilarya, S. Evaluation of a diesel engine optimized by non-evolutionary NLPQL and evolutionary genetic algorithms and assessing second law efficiency: Analysis in exergy loss and chemical exergy. Appl. Therm. Eng. 2019, 159. [CrossRef] 
44. Navid, A.; Khalilarya, S.; Taghavifar, H. Comparing multi-objective non-evolutionary NLPQL and evolutionary genetic algorithm optimization of a DI diesel engine: DoE estimation and creating surrogate model. Energy Convers. Manag. 2016, 126, 385-399. [CrossRef]

45. Chen, Y.; Lv, L. The multi-objective optimization of combustion chamber of DI diesel engine by NLPQL algorithm. Appl. Therm. Eng. 2014, 73, 1332-1339. [CrossRef]

46. Hu, N.; Zhou, P.; Yang, J. Comparison and combination of NLPQL and MOGA algorithms for a marine medium-speed diesel engine optimisation. Energy Convers. Manag. 2017, 133, 138-152. [CrossRef]

47. Hydraulic Cylinders-Heavy Duty Roundline Welded-Series RDH I Malaysia. Available online: https://ph.parker.com/my/ en/heavy-duty-hydraulic-roundline-cylinders-series-rdh (accessed on 19 January 2020).

48. Bladder Accumulator-High Pressure (EHV) I Malaysia. Available online: https://ph.parker.com/my/en/bladder-accumulatorhigh-pressure-ehv (accessed on 19 January 2020).

49. Bladder Accumulator-Low Pressure (EBV Series) I Malaysia. Available online: https://ph.parker.com/my/en/low-pressurebladder-accumulator-ebv (accessed on 19 January 2020).

50. High Torque Radial Piston Motors—Series MR*। Malaysia. Available online: https://ph.parker.com/my/en/high-torqueradial-piston-motors-series-mr (accessed on 19 January 2020). 